\title{
Two-dimensional material-based virus detection
}

\author{
Wenbin Wang ${ }^{1}$, Wei Zhai ${ }^{2}$, Ye Chen ${ }^{3}$, Qiyuan $\mathrm{He}^{1^{*}}$ \& Hua Zhang ${ }^{2,4,5^{*}}$ \\ ${ }^{1}$ Department of Materials Science and Engineering, City University of Hong Kong, Hong Kong, China; \\ ${ }^{2}$ Department of Chemistry, City University of Hong Kong, Hong Kong, China; \\ ${ }^{3}$ Department of Chemistry, The Chinese University of Hong Kong, Shatin, Hong Kong, China; \\ ${ }^{4}$ Hong Kong Branch of National Precious Metals Material Engineering Research Center (NPMM), City University of Hong Kong, \\ Hong Kong, China; \\ ${ }^{5}$ Shenzhen Research Institute, City University of Hong Kong, Shenzhen 518057, China
}

Received September 16, 2021; accepted November 2, 2021; published online January 5, 2022

\begin{abstract}
Cost-effective, rapid, and accurate virus detection technologies play key roles in reducing viral transmission. Prompt and accurate virus detection enables timely treatment and effective quarantine of virus carrier, and therefore effectively reduces the possibility of large-scale spread. However, conventional virus detection techniques often suffer from slow response, high cost or sophisticated procedures. Recently, two-dimensional (2D) materials have been used as promising sensing platforms for the highperformance detection of a variety of chemical and biological substances. The unique properties of 2D materials, such as large specific area, active surface interaction with biomolecules and facile surface functionalization, provide advantages in developing novel virus detection technologies with fast response and high sensitivity. Furthermore, 2D materials possess versatile and tunable electronic, electrochemical and optical properties, making them ideal platforms to demonstrate conceptual sensing techniques and explore complex sensing mechanisms in next-generation biosensors. In this review, we first briefly summarize the virus detection techniques with an emphasis on the current efforts in fighting again COVID-19. Then, we introduce the preparation methods and properties of 2D materials utilized in biosensors, including graphene, transition metal dichalcogenides (TMDs) and other 2D materials. Furthermore, we discuss the working principles of various virus detection technologies based on emerging 2D materials, such as field-effect transistor-based virus detection, electrochemical virus detection, optical virus detection and other virus detection techniques. Then, we elaborate on the essential works in 2D material-based high-performance virus detection. Finally, our perspective on the challenges and future research direction in this field is discussed.
\end{abstract}

two-dimensional materials, virus detection, field-effect transistor, biosensor, COVID-19

Citation: Wang W, Zhai W, Chen Y, He Q, Zhang H. Two-dimensional material-based virus detection. Sci China Chem, 2022, 65: 497-513, https://doi.org/ $10.1007 / \mathrm{s} 11426-021-1150-7$

\section{Introduction}

Throughout the course of history, virus outbreaks have ravaged countless lives and sometimes changed the pace of history. Since the 21 st century, along with the rapid globalization, several highly contagious and fatal viruses, such as the severe acute respiratory syndrome coronavirus (SARS$\mathrm{CoV})$ [1], Ebola [2], influenza virus [3], Zika [4], and most

\footnotetext{
*Corresponding authors (email: hua.zhang@cityu.edu.hk; qiyuanhe@cityu.edu.hk)
}

recently SARS-CoV-2 [5], have posed great threats to the society. As emphasized again during the current COVID-19 pandemic, efficient virus detection plays a critical role in identifying the infected patients from crowds for immediate quarantine and treatment and minimizing the impact to public wellness and global economy. Till now, various virus detection technologies have been developed, which can be generally classified into three categories, i.e., detection of viral particles (virions and viral proteins), detection of antibodies, and detection of viral nucleic acids. However, current 
widely adopted virus-detection methods often show limitations in field applications or in large-scale screening. For example, detection of virions often suffers from procedure complexity and high cost, while antibody and nuclei acids detection techniques are limited by insufficient sensitivity and long analysis time, respectively [6]. In the case of SARS$\mathrm{CoV}-2$, because of its great infectivity and close genetic resemblance to SARS-CoV, detection techniques with largescale accessibility and high sensitivity are highly demanded [7]. Therefore, there is an exigent need for the development of fast, accurate, sensitive and low-cost virus detection techniques for both epidemic control and clinical diagnose.

The last two decades have witnessed the increasing interest of two-dimensional (2D) materials in many fields since Novoselov et al. mechanically exfoliated graphene from graphite [8-11]. Owing to their atomic thickness and unique physicochemical properties, 2D materials have been considered as promising biosensing platforms with exceptional sensitivity. The large specific area due to 2D morphology not only allows high load of analytes or bioreceptors, but also provides abundant interactive sites for viral biomolecules and particles. The excellent electronic, electrochemical and optical properties offer 2D materials biosensors various transducing capability to detect viral analytes from small biomolecules to large virions. In addition, 2D material-based biosensors could potentially implement point-of-care virus detection, overcoming the disadvantages of conventional detection techniques like high cost and complicated procedures. At present, with the rapid development of 2D materials as well as the demand for large-scale and sensitive virus detection, 2D material-based virus detection is facing opportunities in both lab-based research and commercialization in clinical diagnosis and healthcare monitoring. Hence, it is necessary to comprehensively summarize and analyze the advances in 2D material-based virus detection.

In this review, we summarize and evaluate the existing work on 2D material-based virus detection. Firstly, we give a brief introduction of current virus detection techniques and their general principles, with a particular focus on COVID19 diagnosis. In the following section, we summarize the versatile properties, preparation methods, and functionalization approaches of 2D materials including graphene, transition metal dichalcogenides (TMDs), and other 2D materials. Then we analyze the figure of merits of 2D materials towards virus detection based on their unique properties. The working principles of several most-studied 2D material-based virus detection methods (i.e., field-effect transistor-based biosensors, electrochemical biosensors, and optical biosensors) are discussed and the latest advances are reviewed. Finally, we propose the challenges and opportunities in 2D material-based virus detection and provide an outlook of this field. Compared with recent reviews $[7,12]$ on this topic, this review focuses on the preparation, properties and unique functions of 2D materials in virus detection and pays special attention to the virus detection techniques related to the current COVID-19 pandemic.

\section{Virus detection methods: general principles and combating COVID-19}

\subsection{General principles of virus detection}

Viruses are a kind of submicroscopic organisms generally consisting of proteins and nucleic acids, which only replicate inside hosts for the lack of metabolic activities [13]. The viral proteins usually exist in a surface layer named capsid, and sometimes in the outer envelope of the core containing nucleic acid. The viral nucleic acid that virus carries for reproduction can be double-stranded DNA (dsDNA) and RNA (dsRNA) or single-stranded DNA (ssDNA) and RNA (ssRNA). After the infectious virus hijacks a host cell, it utilizes the mechanisms of the host to replicate, transcript, and synthesizes proteins for reproduction and spread, eventually resulting in death of the host cell. Virus isolation and detection techniques have been developed for about 70 years. The earliest virus detection mainly relied on cultivation and electron microscopy $[14,15]$. Although the timeconsuming procedures and expensive facilities hindered the practical use in routine diagnosis [16], these techniques laid the foundation of modern virus detection technologies. In the current stage, three most effective types of virus detection technologies in both laboratory research and clinic diagnosis are the detection of viral particles (virions and viral proteins), antibodies and nucleic acids.

The detection of viral particles is the most straightforward approach to determine the presence of viruses. Transmission electron microscopy (TEM) serves as an effective detection instrument to directly visualize the morphology of virions, while the requirements of specialized sample preparation, technical expertise and expensive equipment hamper its routine utilization for diagnostics [17]. Flow cytometry is another detection technique for viral particles, which was generally applied to investigating infected host cells to indirectly detect viruses because the submicroscopic viral particles are usually too small to be directly detected by classic flow cytometry [18]. These flow cytometry methods have gradually evolved into current highly sensitive flow vitometry technology for the direct detection and analysis of viral microparticles with sizes range from 100 to $1000 \mathrm{~nm}$ [19]. Although the direct detection of viral particles is the most straightforward and accurate way, the existing detection techniques are generally not favorable for practical use because the requirement on complex instrument and highly trained operators.

Besides virions, the viral proteins, which are antigens specified by the viral genome, can also be directly detected. 
These antigens appear immediately in blood circulation after virus infection. Hence, they can be timely detected with some immunoassay methods. Antigen-capture enzymelinked immunosorbent assay (ELISA) is a routine serological technique for the detection of antigens, which has been successful applied to detect various viruses, such as the Zika virus, orthopoxvirus and SARS-CoV-2 [20-22]. Lateral flow assay (LFA) is another classic and popular point-of-care diagnostic platform for antigen detection. In a recent example, LFA was employed to directly detect SRAS-CoV-2 antigens in nasal swabs within $30 \mathrm{~min}$, which offers possibilities for the rapid, cheap and early-stage detection of infectious cases of COVID-19 [23]. However, the antigen detection is currently serving as a supplementary method to others, such as nucleic acids detection, due to its substantially low sensitivity.

Antibody, also known as immunoglobulin (Ig), is a type of protein produced and utilized by the immune system to identify and neutralize viral antigens. Antibody-based serological diagnostics methods such as ELISA, neutralization assay, and immunofluorescence assay, detect virus indirectly by testing the presence of specific antibodies generated by the immune system to fight the corresponding viral antigens. These antibody-based virus detection techniques share a similar working principle, i.e., the conjugation between specific antibodies with various signal systems, such as enzymes, red blood cells, and fluorescence materials. Therefore, antibody-based diagnostics, which is free of sophisticated virus isolation and expensive reagent, is a wellrecognized technique for facile and efficient virus detection. However, the main drawback of these techniques is that a certain time span is required for the immune systems to response after the virus infection, which challenges the reliability and accuracy of virus detection [24]. Currently, antibody-based serological detection is a common approach for viral diseases diagnosis in both clinical application and biomedical laboratories.

Along with the rapid development of nanotechnology and molecular biology, detection of nucleic acids has gradually become the mainstream virus detection method. Nucleic acids can be sensitively detected immediately after virus infection without considering the response of host immune system. Besides, detection of nucleic acids could directly differentiate the subtypes of virus with genetic distinction. In general, detection of nucleic acids requires analytical samples with high quality and quantity that utilize complex sample preparation procedures including cell lysis, DNA/ RNA extraction and amplification. Cell lysis destroys the biological membranes to expose cytoplasm using physical/ chemical approaches, such as high temperature, chemical reagents, electrical field and mechanical force [25]. Thereafter, DNA/RNA are extracted from the cytoplasm (including proteins, polysaccharides, and fat molecules) by extraction methods such as density gradient centrifugation, phenol-chloroform extraction, solid-phase extraction, and magnetic bead method [26]. For some viruses, such as SARS-CoV-2, the viral load in samples would vary with sample type and decrease with infectious time, resulting in insensitive and even false-negative detection [7]. Therefore, DNA amplification, which not only increases the concentration of viral nucleic acids to be more detectable, but also endows possible early clinical detection and diagnosis, is of great importance. Polymerase chain reaction (PCR) is the most popular amplification technique in both clinical diagnosis and laboratory research. The general principle of PCR is the utilization of DNA polymerase to exponentially amplify the specific region of a DNA strand in a series of cycling processes involving denaturation, annealing, and extension under different temperatures [27,28]. For RNA viruses, reverse transcription PCR (RT-PCR) is applied in which a reverse transcriptase is used to convert RNA to complementary DNA before going through similar PCR amplification. Besides PCR, there are several emerging isothermal DNA amplification techniques, such as loop mediated isothermal amplification (LAMP) [29], recombinase polymerase amplification (RPA) [30], and helicase-dependent amplification (HDA) [31]. Yet, all these DNA amplification techniques are still facing certain challenges in practical application more or less related to the cost effectiveness, reliability and processing time. Additionally, there are some other nucleic acid detection methods. For instance, DNA sequencing, which could obtain the information contained in the whole genome and the mutant gene, is a powerful technique with great potential in virus detection $[32,33]$. Other emerging virus detection strategies include virome capture sequencing (VirCapSeq) platform and the Noble prize-winning clustered regularly interspaced short palindromic repeats (CRISPR) technology [34,35].

\subsection{Current virus detection techniques for COVID-19}

The COVID-19 outbreak is caused by SARS-CoV-2, which is classified to the genus $\beta$-coronavirus with positive-sense single-stranded RNA (+ssRNA) as the genetic information carrier. The current detection techniques of SARS-CoV-2 virus can be generally classified to four categories: the nucleotide detection, the virus particle detection, the viral antigen detection assay, and the antibody detection.

In the initial period of combating COVID-19 outbreak, the detection of SARS-CoV-2 was mainly carried out by the nucleotide detection including DNA sequencing technique and the RT-PCR method [7]. DNA sequencing can identify the explicit mutations and the evolution of SARS-CoV-2, but require sophisticated instruments operated by highly skilled researchers over a long period under critical laboratory conditions, limiting their scalable application of identifying 
the infected patients [36]. In contrast, the RT-PCR method is cheaper, more facile and far more efficient, and therefore, is becoming the global standard for SARS-CoV-2 detection after the extensive spread [37]. Many RT-PCR-based detection kits are currently commercially available, often employing multiplex RT-PCR to detect more than two target RNA regions for enhanced selectivity and sensitivity. Multiplex RT-PCR usually contains two steps, the simultaneous transcription of multiple target RNA into complementary DNA by reverse transcriptase, and the massive extension of obtained complementary DNA for further detection. Commercial RT-PCR kits were designed to include RNA extraction, purification, transcription, extension, and detection, which not only grantees the detection accuracy and repeatability but also avoids cross-contamination. Besides, there are some other yet-to-be-commercialized techniques applied in the RNA detection of SARS-CoV-2, such as reversed transcription-LAMP (RT-LAMP) and CRISPR [38-40].

The direct detection of virus particles of SARS-CoV-2 is generally based on immunoassays. One of the most representative work within the scope of $2 \mathrm{D}$ materials is the development of graphene-based field-effect transistors (FETs) for the direct detection of SARS-CoV-2 virus particles based on its binding with anti-spike antibodies [41]. Additionally, the detection of antigen using ELISA and lateral flow assay is another approach for diagnosing COVID19 since the viral antigen can be released in a large amount at the incipient stage of infection $[42,43]$. The nucleocapsid protein, a typical antigen of SARS-CoV-2, was tested to be present in the gargle solution, the nasopharyngeal swabs and urine of COVID-19 patients, which is likely to be an effective way to tentatively identify the infected [44]. The antibody detection assays can be classified to detection of the targeting anti-spike protein and the antibodies targeting antinucleocapsid protein $[7,45]$. Owing to the high similarity in the amine acid sequences of receptor bind regions of SARS$\mathrm{CoV}$ and SARS-CoV-2, and the various immune response time of patients, the sensitivity of antibody detection assays is not absolutely guaranteed [43]. It is reported that the combination of RT-PCR detection and antibody detection can greatly enhance the accuracy of the diagnosis of COVID19 [46].

\section{Preparation and properties of $2 \mathrm{D}$ materials for biosensors}

Inspired by graphene, numerous $2 \mathrm{D}$ materials with unique properties and versatile applications have been developed, such as TMDs, graphitic carbon nitride $\left(\mathrm{g}_{-} \mathrm{C}_{3} \mathrm{~N}_{4}\right)$, metalorganic frameworks (MOFs) and transition metal carbides and/or nitrides (MXenes). 2D materials can be prepared via a variety of preparation strategies which have a huge impact on their properties. In this section, we will first introduce the preparation strategies and related physiochemical properties of all the 2D materials used in virus detection (Figure 1), and then discuss some common 2D material-based virus detection and their corresponding principles as well as characteristic advantages (Figure 2).

\subsection{Preparation strategies of $2 \mathrm{D}$ materials}

Among 2D materials, graphene and TMDs are the most extensively studied in virus detection. Graphene, a single layer of carbon atoms arranged in a honeycomb lattice, is a semimetal with zero bandgap. TMDs, a group of 2D materials with a formula of $\mathrm{MX}_{2}$ (where $\mathrm{M}=$ transition metal, $\mathrm{X}=$ $\mathrm{S}, \mathrm{Se}, \mathrm{Te}$ ), are another emerging class of $2 \mathrm{D}$ materials that attract interest from many research fields. Graphene, TMDs and their derivatives used in virus detection share similar preparation strategies which can be generally categorized into three types: exfoliation, chemical vapor deposition (CVD), and wet-chemical synthesis.

Exfoliation is a top-down fabrication method based on the destruction of interlayer van der Waals interaction in bulk source materials to produce nanosheets from few layers to single layer. It mainly includes mechanical cleavage and liquid exfoliation. Mechanical cleavage, also known as the Scotch tape method, can produce small quantity of ultrathin 2D nanosheets with few defects from layered source crystals, which could be generally applied for almost all 2D materials. On the other hand, liquid exfoliation mainly includes liquid ultrasonication and electrochemical intercalation [47]. Liquid ultrasonication uses solvents whose surface tension is well matched with 2D materials to break the van der Waals interactions via ultrasonication to prepare few-layer nanosheets suspensions. But this method is limited by relatively small lateral size and difficulty in obtaining single layer. Electrochemical intercalation uses electrochemical potential to intercalate ions into the interlayer spacing of bulk 2D crystals to break the van der Waals interaction between layers. This method is generally favored due to its fine control over the intercalation process and high yield. CVD is the most widely used bottom-up synthesis method that enables the direct synthesis of high quality 2D nanosheets on substrates, which is widely adopted for the preparation of graphene and TMDs with controllable morphology and high crystal quality [47]. In addition, reduced graphene oxide (rGO), a popular graphene derived material frequently used in biosensing due to its richness in structural defects and functional groups, is obtained by chemical or thermal reduction of graphene oxide (GO). GO is typically produced by modifications of Hummer's method in which graphite is chemically oxidized and consequently exfoliated into GO nanosheets [48]. Owing to the inert basal plane and intrinsic hydrophobicity, pristine graphene generally requires further 


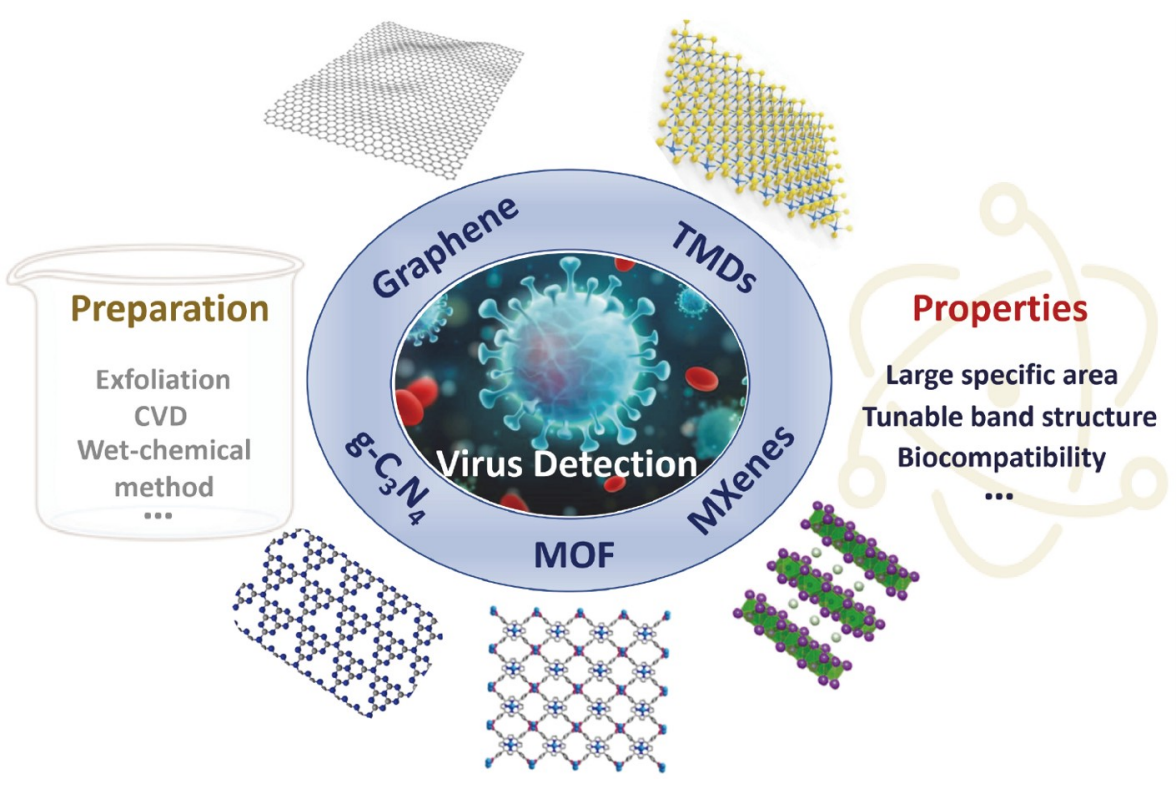

Figure 1 Schematically illustration of the preparation methods and properties of various of 2D materials for virus detection (color online).

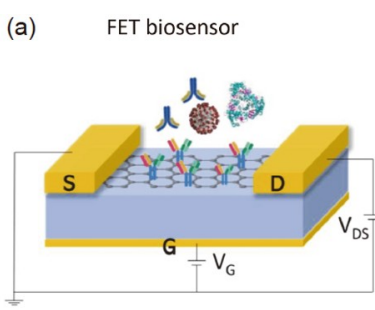

(d)

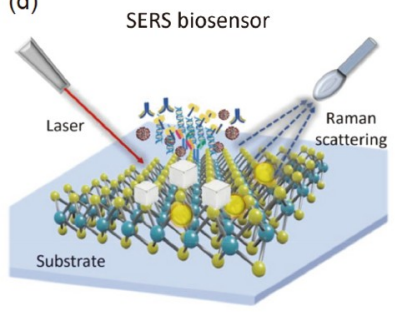

(b) Electrochemical biosensor

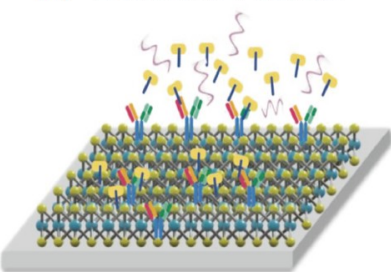

(e)

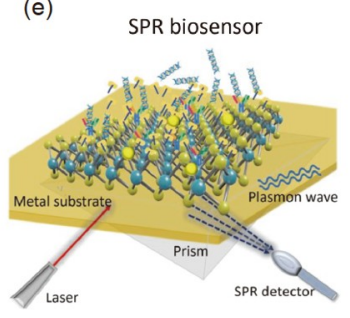

(c)

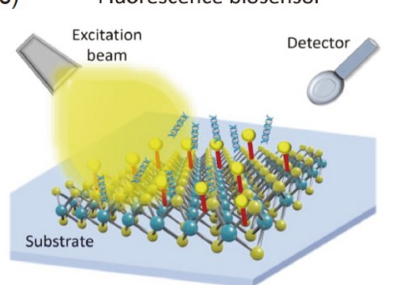

(f)

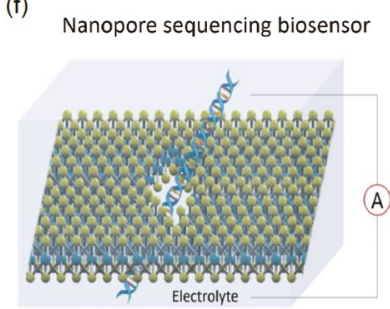

Figure 2 Schematics of 2D material-based biosensors. (a) Field-effect transistor (FET) biosensor; (b) electrochemical biosensor; (c) fluorescence biosensor; (d) surface enhancement Raman spectroscopy (SERS) biosensors; (e) surface plasmon resonance (SPR) biosensors; (f) nanopore sequencing biosensors (color online).

functionalization, covalent or non-covalent, to become suitable for biosensing [49]. On the other hand, TMDs can also be produced in large quantity by wet-chemical methods such as solvothermal or hydrothermal reactions, which are facile, scalable and readily controlled [50]. Like graphene, further functionalization of TMDs is often required before application in biosensing.

Besides graphene and TMDs, other emerging 2D materials have also been employed for virus detection including g$\mathrm{C}_{3} \mathrm{~N}_{4}$, MOFs and MXenes. $\mathrm{g}-\mathrm{C}_{3} \mathrm{~N}_{4}$ is a stable $2 \mathrm{D}$ polymetric semiconductor which only consists of cheap and earthabundant elements, carbon and nitrogen. $g-\mathrm{C}_{3} \mathrm{~N}_{4}$ nanosheets used in virus detection are generally obtained by liquid ex- foliation of bulk source materials synthesized via thermal polycondensation method [51]. g- $\mathrm{C}_{3} \mathrm{~N}_{4}$ can be further functionalized with nanocrystals and quantum dots on the surface for better sensing performance [51,52]. MOFs are a kind of crystalline porous hybrid materials, which consist of metal ions or metal clusters interconnected by organic linkers. MOFs can be synthesized by several bottom-up approaches, such as hydrothermal, solvothermal, microwave-assisted, electrochemical, and sonochemical methods [53]. 2D transition metal carbides, nitrides and carbonitrides, as known as MXenes, are usually synthesized by selectively extracting "A" layers from the precursors of MAX phase (M is transition metal, $\mathrm{A}$ is element in group III A or IV A, and $\mathrm{X}$ is 
carbon or nitrogen) using various hydrofluoric acid (HF)etching or non-HF-etching methods. Similar to other 2D materials, MXenes surfaces are generally modified covalently and noncovalently with abundant functional groups for the application in virus detection [54].

\subsection{Properties and advantages of $2 \mathrm{D}$ materials for biosensors}

In general, 2D material-based biosensors take full advantages of the distinctive electronic, electrochemical, optical, morphological properties, as well as the excellent biocompatibility of 2D materials to detect biospecies with exceptional sensitivity down to molecular level. Specifically, owing to the 2D layered structure, 2D materials possess large specific surface area, which makes them satisfying substrate for biosensors to be functionalized by bioreceptor or interact with analytes in high density. Furthermore, 2D materials often possess excellent biocompatibility, chemical stability and biological stability, which allow extensive incorporation into biological system for in situ monitors or point-of-care devices.

Graphene is a flexible and mechanically strong semimetal with zero bandgap. Graphene possesses excellent electronic, optical and electrochemical properties, which make it the most extensively used 2D materials in biosensing. The ultra-high carrier concentration and mobility, ambipolar charge transport, and more importantly, high transconductance grant exceptional sensitivity in graphene electronic sensors based on FETs. Additionally, the excellent electrochemical properties, such as low charge transport resistance, large electrochemical window, and abundant electrochemical active sites, make graphene ideal electrochemical sensing platform. Moreover, the optical properties like photoluminescence quenching phenomena make graphene intriguing for optical biosensors [55]. Graphene could acquire a variety of specific and neoteric properties after some modification and functionalization, which offer strong versatility in biosensing [56,57].

TMDs, such as $\mathrm{MoS}_{2}$ and $\mathrm{WS}_{2}$, are vital members of the 2D family. Similar to graphene, TMDs display a wide range of properties including tunable electronic/optical properties and engineerable crystal/surface structure, which render great value in developing biosensing techniques. Different from graphene, TMDs could be semiconductors or semimetals depending on chemical composition, oxidation state of the transitional metal atoms and the atomic arrangement [58,59]. More interestingly, some group VIB TMDs, can transfer from semiconductor to semi-metal or metal using various phase engineering approaches. For example, the metastable $1 \mathrm{~T}^{\prime}$-TMD exhibits a remarkable improvement in electrical and electrochemical properties, along with many unique physicochemical properties $[60,61]$. Therefore, the diverse crystal phases of TMDs offer more possibilities for electrochemical virus detection with high selectivity and sensitivity $[62,63]$.

Owing to the chemical stability, decent electronic structure, and medium-band gap, $\mathrm{g}-\mathrm{C}_{3} \mathrm{~N}_{4}$ is often used to develop next-generation biosensors. $\mathrm{g}-\mathrm{C}_{3} \mathrm{~N}_{4}$ also exhibits outstanding electrochemical properties like small electrochemical resistance and abundant active sites [64]. MOFs are considered a promising candidate for optical biosensing owing to the following properties: high fluorescence quenching, high porosity for efficient probe adsorption and adjustable pore size for biomolecule selection, plenty of functional groups and positively charged metal ions provides various interactions with biomolecules, reduced background fluorescence signals with enhanced sensing sensitivity [53]. MXenes have meal-like conductivity decent hydrophilicity, as well as excellent fluorescence quenching properties, which endow them great versatility in biosensing, especially in optical sensing [54].

\subsection{D material-based biosensors: fundamentals and structures}

In this part, we summarize the working principles and advantages of 2D material-based biosensors, which are categorized into FET-based biosensors, electrochemical biosensors, optical biosensors, and other biosensors.

FET-based biosensors, sometimes also referred to as electronic biosensors [65], detect biomolecules or bioactivities based on the conductance/resistance change of the conduxting/semiconducting channel upon direct exposure [66]. The change of the conductance arises from the change of the carrier concentration of semiconductors, resulting from the change of interfacial environment upon interaction with the biomolecules or bioactivities, as shown in Figure 2a. FET-based biosensors offer some key advantages including ultimate sensitivity, real-time response, and label-free detection. However, the sensing performance is largely limited by the bulky semiconductor channels used in FET device that significantly limits its sensitivity. The development of nanomaterials such as silicon nanowires has greatly expanded the capability of FET-based biosensors. In this regard, 2D semiconductors are ideal channel materials in FET-based biosensor due to atomic thickness and large surface area $[67,68]$.

Electrochemical biosensor is a device that utilizes electrochemical reactions to detect biospecies or biointeractions. Figure $2 \mathrm{~b}$ shows the typical structure of an electrochemical biosensor, which detect biomolecules based on the charge transfer process (electrochemical signals due to redox processes) between the biomolecules and the electrode material (active material) in an electrochemical cell. The electrochemical signals arise either from the direct charge transfer between the target biomolecules and the electrode or through 
a functionalized layer on top of the electrode that interacts with target biomolecules. 2D material-based electrochemical biosensors can detect target biomolecules rapidly with high sensitivity and selectivity because of the following characteristics: the easy-functionalization with nanomaterials, large specific surface area for loading analytes, and efficient charge transfer in a wide range of oxidizing and reducing potentials.

Optical biosensors detect the change of optical properties originated from the interaction between 2D material-based probes and biological analytes. Optical biosensors operate under diverse optical transducer systems, including fluorescence (Figure 2c), surface enhancement Raman spectroscopy (SERS) (Figure 2d), and surface plasmon resonance (SPR) (Figure 2e). Fluorescence biosensors based on 2D materials generally utilize the fluorescence quenching capacity of $2 \mathrm{D}$ materials and detect target biomolecules based on the registration of the wavelength and/or the intensity of the fluorescent emission. Specifically, the fluorescent dyes attached with biomolecules could be quenched after the capture by bioreceptors and the consequent interaction with underlying 2D materials. Fluorescent biosensors possess advantages such as low detection limits, high sensitivity, fast detection and portability. On the other hand, SERS biosensors take advantages of both the Raman enhancement and fluorescence quenching of 2D materials to perform real-time and label-free detection of biological analytes with ultrahigh sensitivity. To further increase the sensitivity, 2D materials are usually functionalized with metal nanoparticles to further boost the Raman enhancement. SPR biosensors detect biomaterials by monitoring the shifts in the SPR angle based on the change in the surface refractive index, as a result of the interaction between 2D material functionalized on the prism interface and the biomolecules. 2D materials functionalized on gold thin film in Kretschmann configuration (Figure 2e) is the most popular and commercially available configuration of SPR biosensors.

We pick nanopore sequencing to represent all the other novel biosensors based on 2D materials. As shown in Figure $2 \mathrm{f}$, the nanopore on 2D nanosheet serves as the only transport path for the ions in electrolyte along with the biomolecules. Nanopore-based biosensor detects biomolecules by monitoring the ionic current variation while biomolecules, usually DNA, translocate through the nanopore to change the movement of ions. This novel technique is considered as a next-generation DNA sequencing platform and biosensor platform with good flexibility and high sensitivity.

\section{2D material-based detection of virus}

The distinctive properties of 2D materials, including electrical, electronic, electrochemical, optical, mechanical and morphological properties, offer strong advantages in diverse virus detection techniques. In this section, we will discuss the latest and representative examples of virus detection based on various 2D materials and elaborate on their key figures of merit. The virus detection is categorized into FET virus detection, electrochemical virus detection, optical virus detection, and other virus detection technologies. Table 1 summarizes some representative work on 2D material-based virus detection.

\subsection{Field-effect transistor-based detection of virus}

The portable, fast-response, and label-free FET biosensors are particularly attractive in virus detection, which can directly provide real-time electrical signals from the resistance change of active semiconducting channel upon interaction with target biomolecules. Graphene, TMDs and their derivatives are the most studied 2D materials in FET-based biosensors owing to their large surface area, tunable electrical conduction, as well as facile preparation and functionalization.

Early studies of 2D materials-based electronic biosensors focused on graphene and their derivatives [69], because of their ultrahigh carrier mobilities and high transconductance, enabling the fast and sensitive response. The early development of graphene-based biosensors focuses on proof of concept applications for DNAs and proteins [70], while the first report of graphene FET-based virus detection was for the detection of pathogenic rotavirus [71]. Generally, graphene FET-based biosensors for virus detection are based on the standard antigen-antibody-interaction with some examples on DNA hybridization. The electrical signals were obtained by the variation of resistance of graphene, which is caused by the combination of the antibody attached on graphene and the viral antigen in the sample. In 2017, Chen et al. [72] developed an rGO-based FET biosensor for the realtime detection of Ebola virus antigen, Ebola glycoprotein, the only virally expressed protein on the virion surface. This strategy uses anti-Ebola probes (glycoprotein antibody) immobilized on the surface of rGO to instantaneously capture and detect Ebola glycoprotein down to $1 \mathrm{ng} \mathrm{mL}^{-1}$ in phosphate-buffered saline (PBS), human serum and plasma. Alternatively, Maity et al. [73] reported an innovative method to detect Ebola glycoproteins based on the electronic-resonance-frequency modulation using a dielectric-gated rGO FET. The detection can achieve a high sensitivity by recording the electronic-resonance frequency of the FET at maximum phase angle. The FET biosensor achieved sensitivity of $36 \%-160 \%$ and $17 \%-40 \%$ for $0.001-3.401 \mathrm{mg} \mathrm{L}^{-1}$ Ebola glycoprotein at high and low resonance frequency, respectively. Recently, an rGO FET-based immunoassay was developed by Jin et al. [74] for the detection of inactivated Ebola virus. Equine antibodies against the Ebola glycopro- 
Table 1 Summary of 2D materials-based virus detection

\begin{tabular}{|c|c|c|c|c|}
\hline Type of biosensors & 2D materials & Target viruses/analytes & Limit of detection & Ref. \\
\hline FET & rGO & Ebola & $2.4 \mathrm{pg} \mathrm{mL}^{-1}$ & [74] \\
\hline FET & Graphene & SARS-CoV-2 & $16 \mathrm{pfu} \mathrm{mL}^{-1}$ & [41] \\
\hline FET & $\mathrm{MoS}_{2}$ & Prostate cancer antigen & $100 \mathrm{fg} \mathrm{mL}^{-1}$ & [67] \\
\hline FET & $\mathrm{WSe}_{2}$ & SARS-CoV-2 & $25 \mathrm{pg} \mathrm{mL}^{-1}$ & [84] \\
\hline Electrochemical & rGO & Coxsackie $\mathrm{B} 3$ virus & $0.18 \mathrm{nM}$ & [86] \\
\hline Electrochemical & Graphene & Human immunodeficiency virus & $10 \mathrm{pM}$ & [88] \\
\hline Electrochemical & $\mathrm{MoS}_{2}$ & Chikungunya virus & $3.4 \mathrm{nM}$ & [93] \\
\hline Electrochemical & $\mathrm{g}-\mathrm{C}_{3} \mathrm{~N}_{4}$ & Subgroup J of Avian Leukosis Viruses & $120 \mathrm{TCID}_{50} \mathrm{~mL}^{-1 \text { a) }}$ & [103] \\
\hline Fluorescence & GO & Ebola & $1.4 \mathrm{pM}$ & [106] \\
\hline Fluorescence & $\mathrm{g}-\mathrm{C}_{3} \mathrm{~N}_{4}$ & Influenza A virus & $0.25 \mathrm{pg} \mathrm{mL}^{-1}$ & [112] \\
\hline Fluorescence & $\mathrm{Ti}_{3} \mathrm{C}_{2}$ & Human papillomavirus & $100 \mathrm{pM}$ & [113] \\
\hline SERS & Graphene & hepatitis A virus, hepatitis B virus & $\mathrm{N} / \mathrm{A}^{\mathrm{b})}$ & [120] \\
\hline SERS & Graphene & Norovirus & $5.2 \mathrm{fg} \mathrm{mL}^{-1}$ & {$[122]$} \\
\hline SPR & rGO & Dengue virus & $0.08 \mathrm{pM}$ & [125] \\
\hline Electrochemiluminescence & $\mathrm{g}-\mathrm{C}_{3} \mathrm{~N}_{4}, \mathrm{MOF}$ & Zika virus & $0.1 \mathrm{nM}$ & [131] \\
\hline Colorimetric & GO & Respiratory syncytial virus & $0.04 \mathrm{pg} \mathrm{mL}^{-1}$ & [130] \\
\hline Nanopore-based sensing & graphene & Antibody subclasses $\operatorname{IgG} 2$ and $\operatorname{IgG} 3$ & $\mathrm{~N} / \mathrm{A}$ & [147] \\
\hline Photoelectrochemical & $\mathrm{g}-\mathrm{C}_{3} \mathrm{~N}_{4}, \mathrm{MoS}_{2}$ & Human T-cell lymphotropic virus type II & $0.32 \mathrm{pM}$ & [149] \\
\hline
\end{tabular}

a) $\operatorname{TCID}_{50}: 50 \%$ tissue culture infective dose; b) not applicable.

tein were immobilized on the surface of rGO. This immunoassay can detect the Ebola virus over the concentration ranging from $2.4 \times 10^{-12}$ to $1.2 \times 10^{-7} \mathrm{~g} \mathrm{~mL}^{-1}$ with a limit of detection (LOD) as low as $2.4 \mathrm{pg} \mathrm{mL}^{-1}$. In combating the emerging COVID-19 outbreak, graphene FET was utilized for the detection of both SARS-Cov-2 virus and its antibodies. A typical work was reported by Seo et al. [41] that a FET biosensor with a specific antibody against the SARSCoV-2 spike protein was coated on graphene channel (Figure 3a). This FET sensor successfully detected SARS-CoV-2 in both culture medium and clinical sample with a low LOD of $1.6 \times 10^{1} \mathrm{pfu} \mathrm{mL}^{-1}$ and $2.42 \times 10^{2}$ copies $\mathrm{mL}^{-1}$, respectively (Figure 3b). Zhang et al. [75] also developed a sensitive FET immunosensor for the rapid detection of SARS-CoV-2 within 2 min with a LOD of $0.2 \mathrm{pM}$. Besides, graphene FET was applied to the detection of other viruses, such as the human papillomavirus, the avian influenza virus (AIV), the Japanese Encephalitis virus (JEV), and the human immunodeficiency virus [76-80]. For example, Roberts et al. [78] developed a compact and user-friendly graphene FET biosensor for the detection of JEV and AIV. The biosensor detects JEV and AIV in real time by monitoring the change in channel resistance due to antigen-antibody interaction with the LOD of 1 and $100 \mathrm{fM}$, respectively. In addition to antigen-antibody recognition, graphene FETs also detect virus based on viral gene. For instance, Chan et al. [81] reported a microfluidic integrated rGO FET for the detection of H5N1 influenza virus gene. The developed sensor utilized an extended long-capture probe (ssDNA) immobilized on rGO surface to detect target viral DNA in complex environment with excellent sensitivity and robustness.

Nonetheless, the lack of band gap in graphene could means high energy consumption in graphene FET sensor as a result of high off current, which is not ideal for specific application such as point-of-care devices. Comparatively, TMD semiconductors with tunable band gaps may gain an edge in certain scenarios. Early in 2014, Sarkar et al. [82] pointed out that $\mathrm{MoS}_{2}$, the most studied TMD semiconductor, holds high potential in next-generation label-free FET biosensors. Thereafter, Park et al. demonstrated ex-situ prostate cancer (PSA) detection in a nonaqueous environment on $\mathrm{MoS}_{2}$ based FET [67]. The mechanically exfoliated $\mathrm{MoS}_{2}$ nanosheet was uniformly functionalized with chemisorbed anti-PSA antigens. The proposed FET biosensor can readily detect PSA in various concentrations with a LOD of $100 \mathrm{fg} \mathrm{mL}^{-1}$ [67]. In addition, Liu et al. [83] used CVDgrown single-layer $\mathrm{MoS}_{2}$ films functionalized with gold nanoparticles (AuNP) to fabricate FET biosensors for the detection of target DNA fragment of Down syndrome with a high specificity, a high response up to $240 \%$ and a LOD below 100 aM. Most recently, Fathi-Hafshejani et al. [84] reported the development of a FET biosensor based on single-layer $\mathrm{WSe}_{2}$ for the in vitro detection of SARS-CoV-2 (Figure 3c). Monoclonal antibodies against SARS-CoV-2 spike protein were immobilized on single-layer $\mathrm{WSe}_{2}$ using 11-mercaptoundecanoic acid (MUA) as probe linkers. This sensitive FET-based $\mathrm{WSe}_{2}$ biosensor achieved a LOD of $25 \mathrm{fg} \mu \mathrm{L}^{-1}$ in $0.01 \times$ PBS. 
(a)

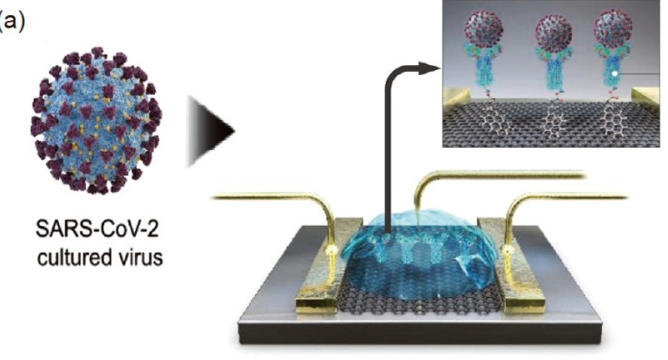

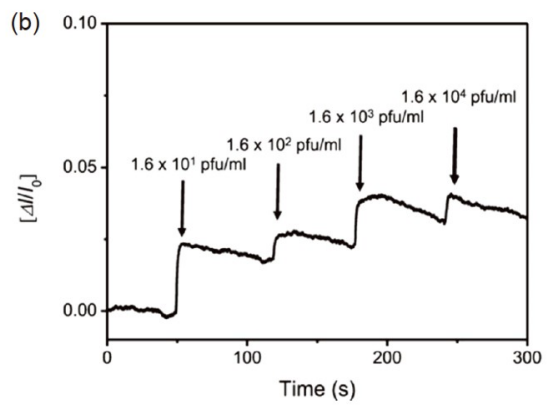

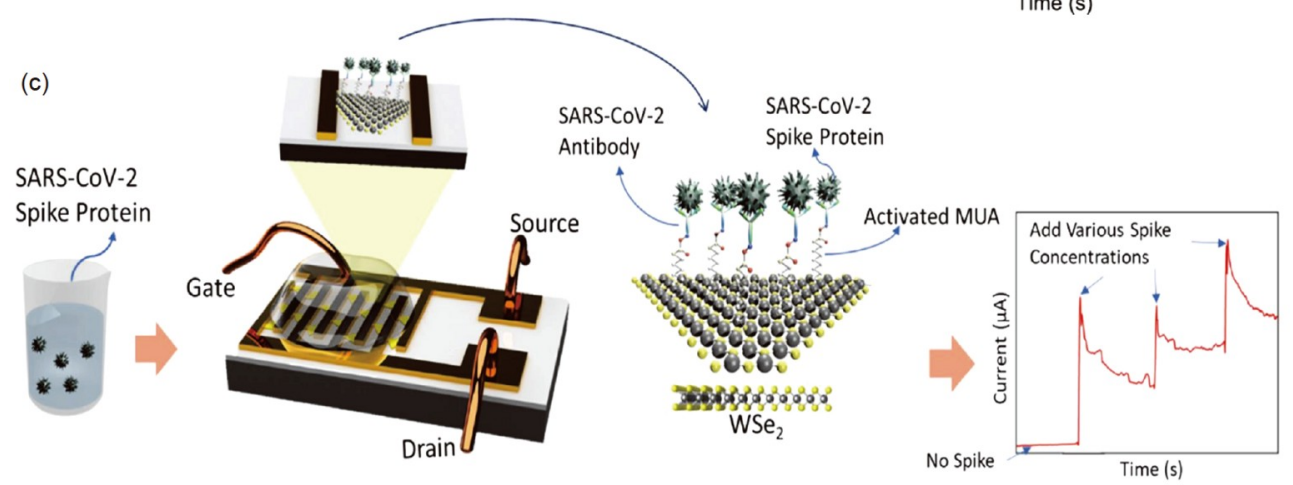

Figure 3 2D material-based FET detection of virus. (a) Schematic of the graphene-based FET sensor for detection of SARS-CoV-2. (b) Real-time response of the FET device toward SARS-CoV-2. Reproduced with permission from Ref. [41], copyright by American Chemical Society (2020). (c) Schematic of the single-layer $\mathrm{WSe}_{2}$-based FET sensor and the corresponding electrical signals during the detection of SARS-CoV-2. Reproduced with permission from Ref. [84], copyright by American Chemical Society (2021) (color online).

\subsection{Electrochemical detection of virus}

Electrochemical virus detection takes advantage of both the versatile electrochemical methods and the unique properties of $2 \mathrm{D}$ materials to direct detect the existence of specific viral molecules, such as the nucleic acids, antigens and antibodies. Herein, we will introduce two mainstream types of electrochemical viral sensing methods based on 2D materials: the DNA hybridization and the antigen-antibody recognition.

DNA hybridization method is generally based on the difference in affinity between ssDNA and dsDNA when adsorbed on 2D materials. Typically, ssDNA naturally was adsorbed on the surface of 2D materials like graphene via hydrogen bonding and $\pi-\pi$ stacking, and TMDs via van der Waals force [85]. Meanwhile, dsDNA has low affinity and weak absorption to $2 \mathrm{D}$ materials because the nucleobases are buried in the densely negatively charged helical phosphate backbone. This difference in absorption affinity will result in the change of either the electrochemical behaviors of the DNA itself or the redox species in the solution, which gives detectable electrochemical signals. Nagar et al. [86] utilized wax-printing technique to fabricate an $\mathrm{rGO} / \mathrm{AuNPs}$ composite-based impedimetric electrochemical biosensor for the detection of ssDNA mark of Coxsackie B3 virus. Electrochemical impedance spectroscopy (EIS) was used to monitor the change of charge transfer resistance after hybridization between the probe ssDNA functionalized with AuNPs and the target Coxsackie B3 ssDNA. A LOD of $0.18 \mathrm{nM}$ and a linear response range of $0.01-20 \mu \mathrm{M}$ were achieved. Li et al. [87] proposed a sensitive electrochemical detection method for the ssDNA mark of hepatitis $\mathrm{C}$ virus (HCV) gene based on a magnetic rGO-Cu nanocomposite. Using EIS measurement, this strategy can effectively distinguish the $1 \mathrm{~b}$ and $6 \mathrm{k}$ subtypes of HCV over a wide linear range of $0.5-10 \mathrm{nM}$ with a LOD of $405 \mathrm{pM}$. Alternatively, the DNA hybridization could be monitored using some electroactive redox indicators, whose oxidization and reduction can provide observable electrochemical signals. For example, Gong et al. [88] reported the detection of HIV by immobilizing ssDNA probes on a polyaniline/graphene modified glassy carbon electrode. The dsDNA formed by hybridization of the ssDNA probe and the target HIV gene altered the charge transfer resistance of the electrode, which can be recorded by EIS measurement with a $\left[\mathrm{Fe}(\mathrm{CN})_{6}\right]^{3-/ 4-}$ redox couple. It was found that the change of impedance value is related to the logarithm of the HIV genes concentration with a linear range from $5.0 \times 10^{-16}$ to $1.0 \times 10^{-10} \mathrm{M}$ and a LOD of $1.0 \times$ $10^{-16} \mathrm{M}$. Another good example is the development of a label-free electrochemical biosensor for hepatitis $\mathrm{B}$ virus (HBV) based on the graphene quantum dot (GQD)-modified glassy carbon electrode [89]. In this work, a specific ssDNA probe-modified electrode was used to detect the target HBV gene. In the absence of target HBV DNA, the DNA probe strongly binds to the GQDs, which impedes the electron transfer from the electrode to $\mathrm{K}_{3}\left[\mathrm{Fe}(\mathrm{CN})_{6}\right]$, a electrochemically active species in the electrolyte. With the pre- 
sence of target HBV, ssDNA probe binds with target HBV ssDNA instead of the GQDs, promoting the electron transfer from the electrode to $\mathrm{K}_{3}\left[\mathrm{Fe}-(\mathrm{CN})_{6}\right]$, which can be monitored by using the differential pulse voltammetry (DPV). As a result, a linear detection from 10 to $500 \mathrm{nM}$ and a LOD of $1 \mathrm{nM}$ were achieved [89]. Other than graphene, TMDs-based electrochemical virus detection based on DNA hybridization is emerging lately [90-92]. Singhal et al. [93] designed a $\mathrm{MoS}_{2}$-based screen-printed gold electrode for chikungunya virus detection using electrochemical voltammetric techniques. This sensor exploited the different interactions of methylene blue with ssDNA and dsDNA, which resulted in the change of the magnitude of the voltammetric signals.

The second detection category based on the antibody-antigen specific recognition interaction offers another convenient way for detecting viruses with high sensitivity and selectivity, which enables the more extensive applications of this technique in recent years [94-98]. As shown in Figure 4, a label-free electrochemical immunosensor was developed by integrating rGO into a novel microfluidic chip to detect influenza virus, H1N1. Monoclonal antibody, a specific type of antibody against H1N1, was functionalized onto the electrode to recognize H1N1. By using chronoamperometric current measurements, a linear range from 1 to $104 \mathrm{pfu} \mathrm{mL}^{-1}$ and a LOD of 0.5 pfu $\mathrm{mL}^{-1}$ were achieved [99]. In another example, taking advantage of the large surface area, an electrochemical immunosensor was developed based on a $\mathrm{Cu}$ (I)/Cu(II)-chitosan-graphene compound for the high loading of both the antibodies and $\mathrm{Cu}(\mathrm{I}) / \mathrm{Cu}(\mathrm{II})$ electroactive probes, resulting in signal amplifying in Newcastle disease virus (NDV) detection [100]. Besides graphene, TMD-based electrochemical biosensors for virus detection are drawing increasing attention. In 2017, Su et al. [101] developed a label-free immunosensor to detect carcinoembryonic antigen (CEA) based on $\mathrm{MoS}_{2}$ nanosheets decorated by Prussian blue nanocubes. The peak current of DPV signals of this immunosensor was found to be linearly related to the logarithm of the CEA concentration in the range from 0.005 to $10 \mathrm{ng} \mathrm{mL}{ }^{-1}$ with a LOD of $0.54 \mathrm{pg} \mathrm{mL}^{-1}$. Recently, Li et al. [102] reported an electrochemical immunosensor for the determination of porcine diarrhoea virus (PEDV) based on AuNP/MoS $2 /$ rGO nanocomposites modified on glassy carbon electrode. The presence of PEDV can be recognized by the monoclonal antibodies of PEDV-2C11 immobilized on electrode at sites of AuNP. Furthermore, $\left[\mathrm{Fe}(\mathrm{CN})_{6}\right]^{3-/ 4-}$ redox probe was applied to quantify the concentration of PEDV by the variation in the charge transfer resistance in EIS measurement of the electrode before and after the specific immunoreaction between antigen and antibody. Other 2D materials were also applied for electrochemical immunosensors of virus detection, such as $\mathrm{g}-\mathrm{C}_{3} \mathrm{~N}_{4}$ and MOFs $[103,104]$. For example, Zhou et al. [103] reported an electrochemical immunosensor based on mesoporous $\mathrm{g}^{-} \mathrm{C}_{3} \mathrm{~N}_{4}$ (mpg- $\mathrm{C}_{3} \mathrm{~N}_{4}$ ) to detect the antibodies of subgroup $\mathrm{J}$ of avian leukosis viruses (ALVs-J). The as-prepared $\mathrm{mpg}_{-} \mathrm{C}_{3} \mathrm{~N}_{4}$ has more active sites, larger specific surface area, and smaller electrochemical resistance in comparison with bulk $\mathrm{g}-\mathrm{C}_{3} \mathrm{~N}_{4}$, resulting in a highly sensitive ALVs-J detection. Overall, the specific antigen-antibody recognition-based viral detection demonstrates features including high sensitivity, high selectivity, fast response and low cost, holding great promise for future clinic application.

\subsection{Optical detection of virus}

Optical biosensing techniques are attractive owing to advantages such as real-time readout, high specificity, high sensitivity, biocompatibility, portability, scalability, and low cost. 2D materials are attracting attention in diverse optical viral detection owing to their many remarkable physicochemical properties, which can be generally categorized into fluorescence biosensors, SPR biosensors, SERS biosensors, and other biosensors.

\subsubsection{Fluorescence detection of virus}

Fluorescent biosensors are the most extensively studied 2D material-based optical virus detection system, which are generally based on the highly efficient fluorescence quenching of 2D materials. Specifically, fluorescent dyes are attached to either the bioreceptors (usually ssDNA) to form fluorescent probes or target biomolecules. The fluorescence emitted from the probes can be quenched by interacting with 2D materials primarily relying on the principle of fluorescence resonance energy transfer (FRET). Upon the hybridization of the bioreceptors and targets, such as nucleic acids, proteins and antigens [105], fluorescence can be restored and detected.

Wen et al. [106] developed a highly sensitive fluorescence biosensor using a GO-assisted rolling circle amplification (RCA) platform for the detection of Ebola with a LOD of $1.4 \mathrm{pM}$. The fluorescein amidate (FAM)-labelled ssDNA probes will spontaneously attach to the GO surface via hydrogen bonding and/or $\pi-\pi$ stacking. The fluorescence was quenched by GO in the absence of Ebola virus gene. The addition of the Ebola virus gene triggered the RCA process and consequently formed dsDNA between RCA products and FAM-labelled probes, resulting in the desorption of FAM-labelled probes from GO surface as well as the simultaneous fluorescence recovery. In another example, Waiwijit et al. [107] reported a fluorescence biosensor for the detection of white spot syndrome virus (WSSV)-DNA based on LAMP, another emerging DNA amplification technique, and FRET between GO and the fluorescein isothiocyanatelabeled probe (FITC probe). The fluorescence intensity of FITC-probe recovered after hybridization between WSSV LAMP products and FITC probes within an optimal hy- 


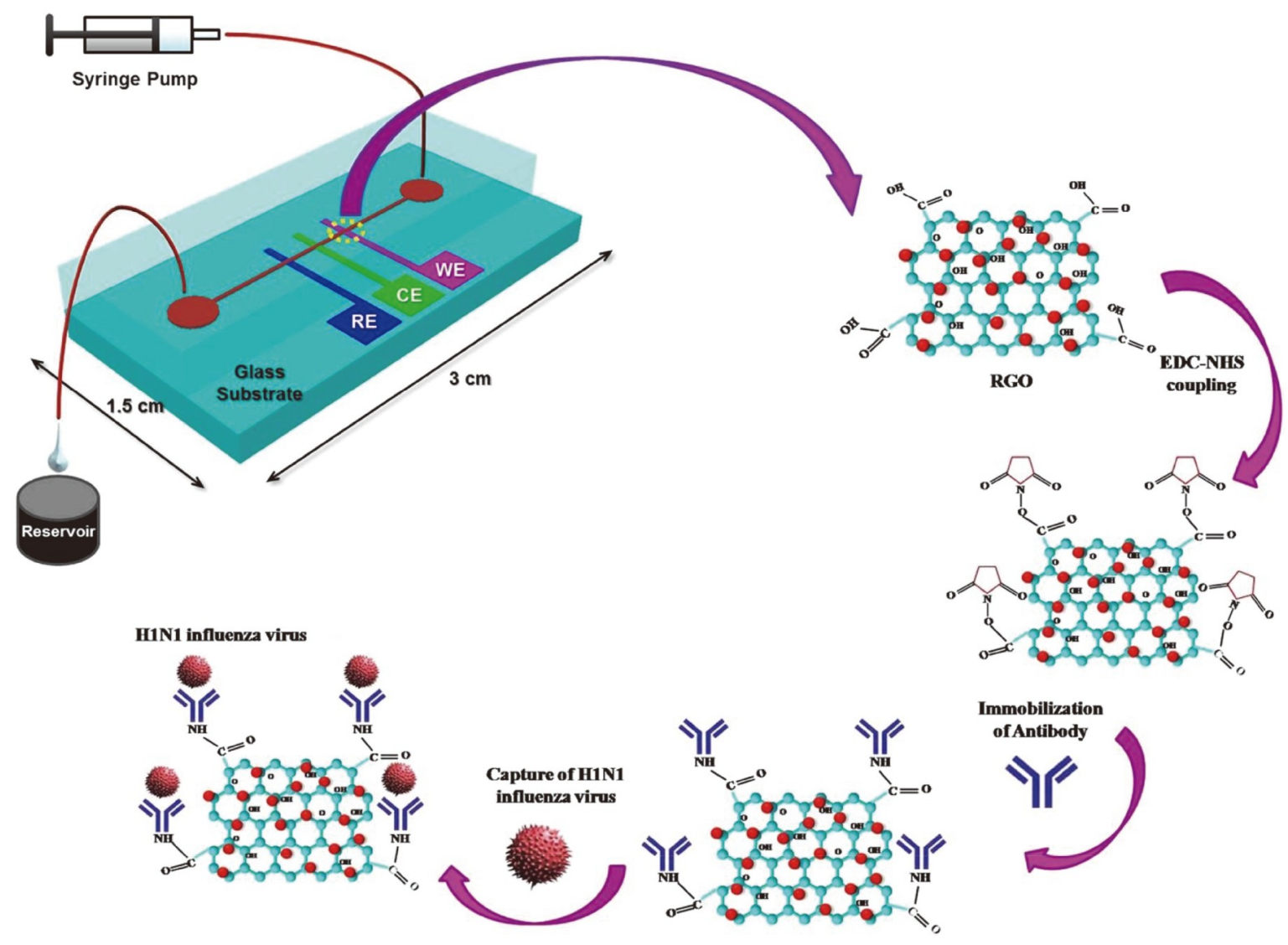

Figure 4 2D material-based electrochemical detection of virus. Schematic of the microfluidics-integrated electrochemical immunosensing chip. The sensing chip was coated with rGO, consequently conjugated with antibodies via EDC/NHS coupling, and used for the detection of influenza virus H1N1. Reproduced with permission from Ref. [99], copyright by Springer Nature (2017) (color online).

bridization time. The LOD of this virus detection technique was estimated to be 10 copies of WSSV plasmid DNA, i.e., $0.6 \mathrm{fg}$ of the total DNA extracted from WSSV-infected shrimp. Compared with graphene and its derivatives, some TMDs exhibit more effective florescence quenching capability $[108,109]$. Kenry et al. [110] demonstrated an aptamer-based fluorescence biosensor for the detection of Plasmodium lactose dehydrogenase $(\mathrm{pLDH})$ protein, a Malarial biomarker, by using single-layer $\mathrm{MoS}_{2}$ nanosheet (Figure 5). The developed biosensor was capable of rapidly detecting the target $\mathrm{pLDH}$ proteins within $10 \mathrm{~min}$ with a LOD of approximate $550 \mathrm{pM}$. The pLDH could be selectively detected in both homogeneous protein solutions and in heterogeneous mixtures of proteins. Remarkably, the in situ detection of target microRNAs (miRNAs) expression in single living cancer was reported using $\mathrm{MoS}_{2}$ nanosheets modified with a dye-labelled [111]. The detachment of the ssDNA probe from $\mathrm{MoS}_{2}$ surface, as a result of the hybridization with target miRNAs, leads to the recovery of the green fluorescence. The employment of $\mathrm{MoS}_{2}$ demonstrated several advantages in real-time clinic applications including highly efficient fluorescence quenching, high stability, and supremely low biotoxicity. Recently, similar detection based on other 2D materials was reported. For instance, a magnetic/ plasmonic-assisted fluoroimmunosensor platform was developed by Achadu et al. [112] for the detection of influenza A virus. The fluorescent $\mathrm{g}-\mathrm{C}_{3} \mathrm{~N}_{4}$ quantum dots (QDs) were functionalized with specific antibodies against influenza $\mathrm{A}$ virus as the fluorescent probe and further conjugated with magnetic-derivatized plasmonic $\mathrm{MoO}_{3}$. The $\mathrm{MoO}_{3}$ QDs exhibited magnetism and localized surface plasmonic resonance, which are responsible for the magnetic separation of target virus and fluorescence signal enhancement, respectively. At the presence of influenza A viruses, the interaction between virus and the antibodies on $\mathrm{g}^{-} \mathrm{C}_{3} \mathrm{~N}_{4} / \mathrm{MoO}_{3}$ conjugation resulted in the shift of fluorescence peak position and enhancement of fluorescence intensity. In another example, rapid detection of Human papillomavirus (HPV) was reported by Peng et al. [113] using a fluorescence biosensor based on MXene $\left(\mathrm{Ti}_{3} \mathrm{C}_{2}\right)$ nanosheets. The dye-labelled ssDNA probe showed the minimal fluorescent emission because the $\mathrm{Ti}_{3} \mathrm{C}_{2} \mathrm{NSs}$ can effectively quench the fluorescence, while displayed enhanced fluorescence after hybridizing with target HPV ssDNA. The MXene-based fluorescence sensor exhibited a LOD of 100 pM for HPV-18 with a high selectivity. 

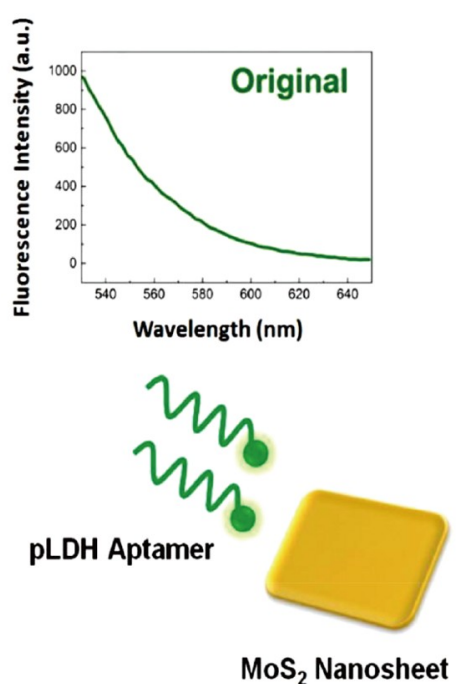

MoS $_{2}$ Nanosheet
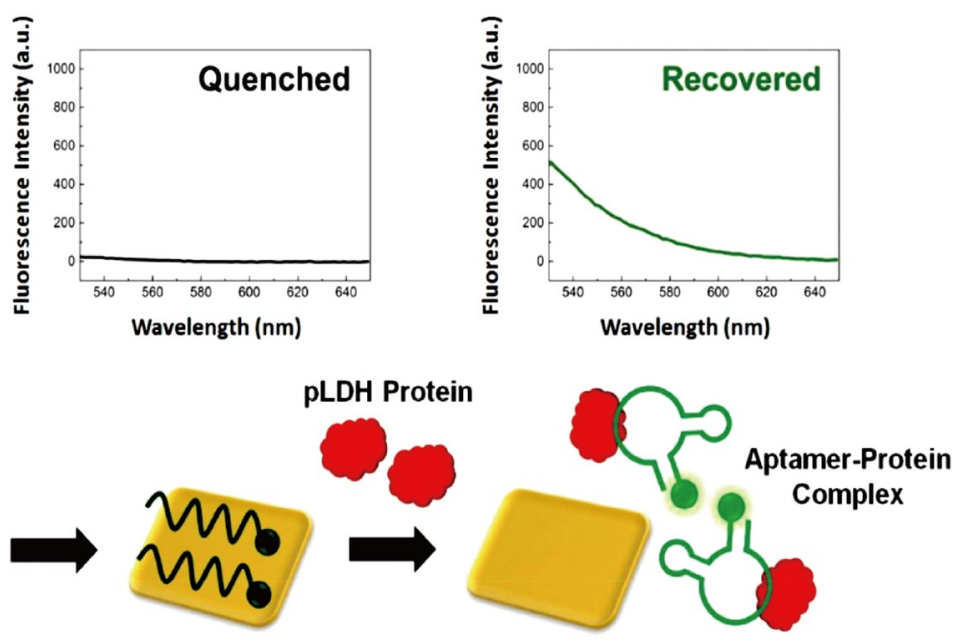

Figure 5 2D material-based fluorescence detection of virus. Schematic of the aptamer-based "capture-release" sensing assay for the fluorescence detection of pLDH using $\mathrm{MoS}_{2}$ nanosheets. Top panels: the corresponding fluorescence spectra during the sensing process. Reproduced with permission from Ref. [110], copyright by American Chemical Society (2016) (color online).

\subsubsection{SERS detection of virus}

Since the first report of single-layer graphene as SERS substrate back in 2009, SERS biosensors based on 2D materials, such as MXene, $\mathrm{WS}_{2}, \mathrm{~g}-\mathrm{C}_{3} \mathrm{~N}_{4}, \mathrm{~h}-\mathrm{BN}$, and $\mathrm{MoS}_{2}$, have attracted considerable attention [114-119]. Although 2D materials usually display moderate SERS enhancement factors of only 10-100, their fluorescence quenching property makes them ideal substrates to support other SERS-active nanomaterials to achieve optimal sensitivity in biosensing.

A SERS active substrate based on AuNPs decorated CVDgrowth graphene was recently reported and used in multiplexing DNA detection. The AuNPs functionalized graphene can easily immobilize high density of ssDNA probes for enhanced sensitivity. The developed biosensor displayed strong SERS signals only at the presence of target DNA with a LOD as low as $10 \mathrm{pM}$ [120]. In another example, GO was modified by silver NPs (AgNPs) to enhance the Raman scattering intensity in both $\mathrm{D}$ and $\mathrm{G}$ bands [121]. An enzyme was introduced to produce hydrogen peroxide $\left(\mathrm{H}_{2} \mathrm{O}_{2}\right)$ for the dissolution of AgNPs on GO surface, which induces the decline of the GO Raman signal. The sensitivity of the biosensor was greatly enhanced by the dual signal amplification of the enzyme and AgNPs. This SERS biosensor successfully detected prostate specific antigen (PBS) in the range from 0.5 to $500 \mathrm{pg} \mathrm{mL}^{-1}$ with a LOD of $0.23 \mathrm{pg} \mathrm{mL}^{-1}$. Similar to the use of $\mathrm{MoO}_{3}$ QDs in fluorescence sensor [112], the plasmonic and magnetic $\mathrm{MoO}_{3}\left(\mathrm{mag}-\mathrm{MoO}_{3}\right)$ nanocubes were also utilized in graphene-based SERS immunoassay for the detection of norovirus (NoV) due to their plasmonic SERS enhancement and magnetic separating capacity [122]. As shown in Figure 6, NoV-specific antibody was functionalized on the mag- $\mathrm{MoO}_{3}$ nanocubes and served as both nanotag in SERS detection and the active material in the immunomagnetic separation. Graphene served as both the substrate and the signal reporter, which was also capable of accommodating an additional Raman active molecule (4mercaptobenzoic acid) as the co-reporter. The developed biosensor achieved a signal amplification as high as $\sim 10^{9}$ fold due to the collaborative contribution of the $\mathrm{MoO}_{3}$ SERS nanotag and graphene substrate, achieving a highly sensitively NoV detection in a wide linear range of concentration from $10 \mathrm{fg} \mathrm{mL}^{-1}$ to $100 \mathrm{ng} \mathrm{mL}^{-1}$ with a LOD of $\sim 5.2 \mathrm{fg} \mathrm{mL}^{-1}$.

\subsubsection{SPR detection of virus}

SPR biosensor is built on the basic principle of the shift in the SPR angle once the change in the surface refractive index occurs upon biomolecule binding. SPR biosensor is favored owing to its real-time readout, high sensitivity, and label-free detection. Recently, functionalized 2D materials are emerging to construct SPR biosensors, especially for virus detection with excellent sensitivity [123].

Omar et al. [124-126] did some impressive work in the detection of Dengue Virus (DENV) using functionalized graphene-based SPR biosensors. For example, they reported a SPR sensor based on a dithiobis (succinimidyl undecanoate, DSU)/amine-functionalized rGO-polyamidoamine dendrimer thin film to detect DENV type 2 E-proteins [124]. The developed SPR biosensor displayed a good linearity with the concentration of DENV-2 E-proteins in the range of $0.08-0.5 \mathrm{pM}$ and excellent selectivity. Meanwhile, Chiu et al. [127] demonstrated a carboxyl-functionalized GO (GO$\mathrm{COOH})$ composites-based SPR immunosensor for the detection of Bovine Serum Albumin (BSA). The GO-COOH can modulate the visible spectrum and alter the plasmonic coupling of the SPR interface, resulting in enhanced shifts in 


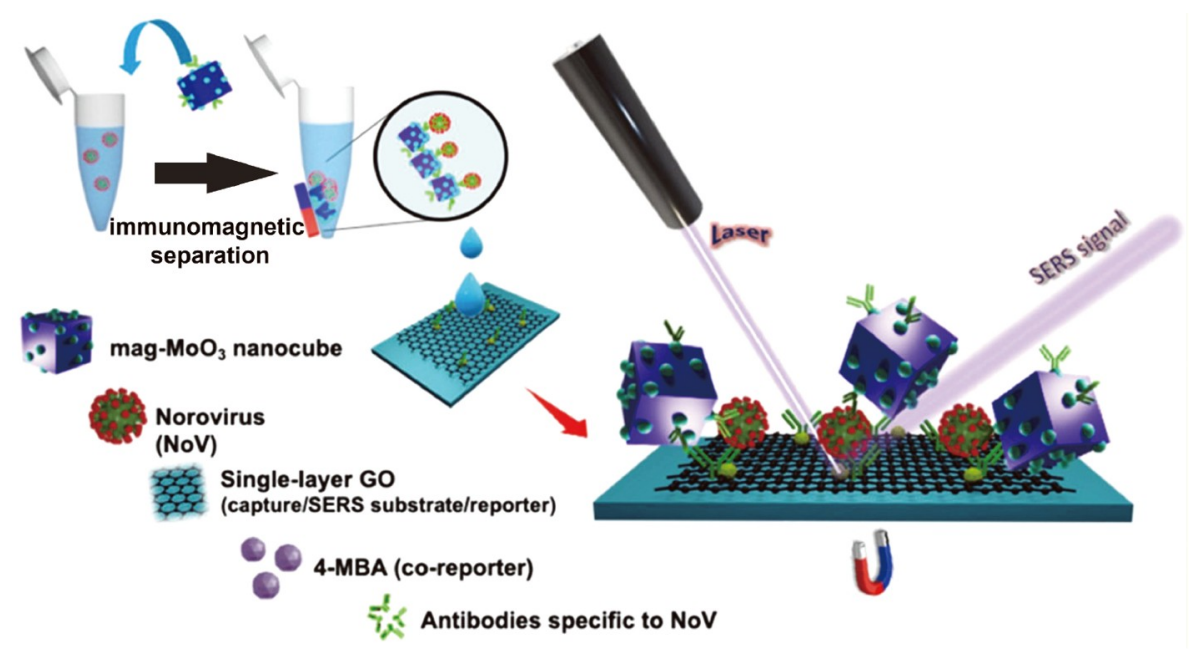

Figure 6 2D material-based SERS detection of virus. Graphical illustration of the NoV detection protocol via the mag-MoO ${ }_{3}$ nanocubes-graphene-mediated SERS biosensor. Reproduced with permission from Ref. [122], copyright by American Chemical Society (2020) (color online).

SPR angles for the GO-COOH-based biosensor compared with the GO-based biosensor. In addition, the GO-COOH also offers large specific surface area and high biocompatibility which enhanced the antigen-antibody interactions during biosensing. The same group further explores novel 2D materials like $\mathrm{MoS}_{2}$ in SPR immunosensor to detect BSA [128]. Nie et al. [129] proposed a highly sensitive SPR biosensors based on the AuNPs-decorated $\mathrm{MoS}_{2}$ to detect microRNA. The developed SPR sensor exhibited high sensitivity towards microRNA with a detection limit of $0.5 \mathrm{fM}$, which could be used for early clinical diagnosis of disease like cancer.

\subsubsection{Other optical detection of virus}

Besides the fluorescence, SERS, and SPR optical virus detection discussed above, there are other optical virus detection techniques based on 2D materials including electrochemiluminescence (ECL) biosensors and colorimetric biosensors [130-132]. For example, Zhang et al. [131] established an ultrasensitive ECL biosensor to detect RNA using metal-organic gels (MOGs) as electrode matrix and MOFs as nanotag. Zr-based MOGs were in-situ loaded with $\mathrm{g}-\mathrm{C}_{3} \mathrm{~N}_{4}$ followed by the assembly of AuNPs, which exhibited excellent solid-state ECL efficiency. Then, DNA probes containing apurinic/apyrimidinic (AP) sites were used to connect the MOGs and MOFs, leading to the turning off of the ECL signal. Once the target Zika virus RNA was added, the ECL can be turned on because the AP site of DNA probes can be activated and circularly cleaved in the presence of endonuclease IV. This ECL biosensor detected Zika virus RNA with a broad detection range from $0.3 \mathrm{nM}$ to $3 \mu \mathrm{M}$ and a LOD of $0.1 \mathrm{nM}$. On the other hand, Zhan et al. [130] developed a novel colorimetric immunoassay on the basis of the $\mathrm{Hg}^{2+}$-stimulated peroxidase-like activity of AuNPs-GO hybrids. The colorimetric biosensor was able to spectro- photometrically detect respiratory syncytial virus (RSV) from 0.1 to $10 \mathrm{pg} \mathrm{mL}^{-1}$ with a LOD of $0.04 \mathrm{pg} \mathrm{mL}^{-1}$.

\subsection{Other virus detection technologies based on 2D materials}

The afore-mentioned FET biosensors, electrochemical biosensors, and optical biosensors are extensively studied, taking up majority of 2D material-based virus detection technologies. On the other hand, nanopore-based sequencing/sensing is an emerging sensing technique aiming to detect biomaterials at molecular level. Specifically, the solidstate nanopore biosensors are considered as the next-generation DNA sequencing tool and single-molecule detecting platform with high specificity and sensitivity [133-135]. 2D materials like graphene and TMDs are natural candidates in nanopore sensing mainly due to their ultrathin morphology [136-139]. For instance, a graphene-based nanopore biosensor exhibited much higher sensitivity compared with conventional $\mathrm{SiN}$ nanopore of similar diameter for dsDNA sequencing $[140,141]$. Besides the general device structure of nanopore biosensor illustrated in Figure 2f, a novel nanopore biosensor was designed to detect DNA molecules by correlating the signals of the ionic current through the nanopore and the transverse current through the 2D materials [138]. As shown in Figure 7a, the ionic current of the nanopore on $\mathrm{MoS}_{2}$ surface and the drain-source current (transverse current) through the $\mathrm{MoS}_{2}$ channel can be simultaneously monitored and correlated for enhanced performance [134]. Aside from the efficient DNA/RNA sequencing, nanopore biosensors have lately been employed in the detection of virus particles and virus specific biomolecule, like antibodies and proteins [142-146]. For example, Farimani et al. [147] developed a single-atom thick graphene nanopore for antibody detection by monitoring the ionic 

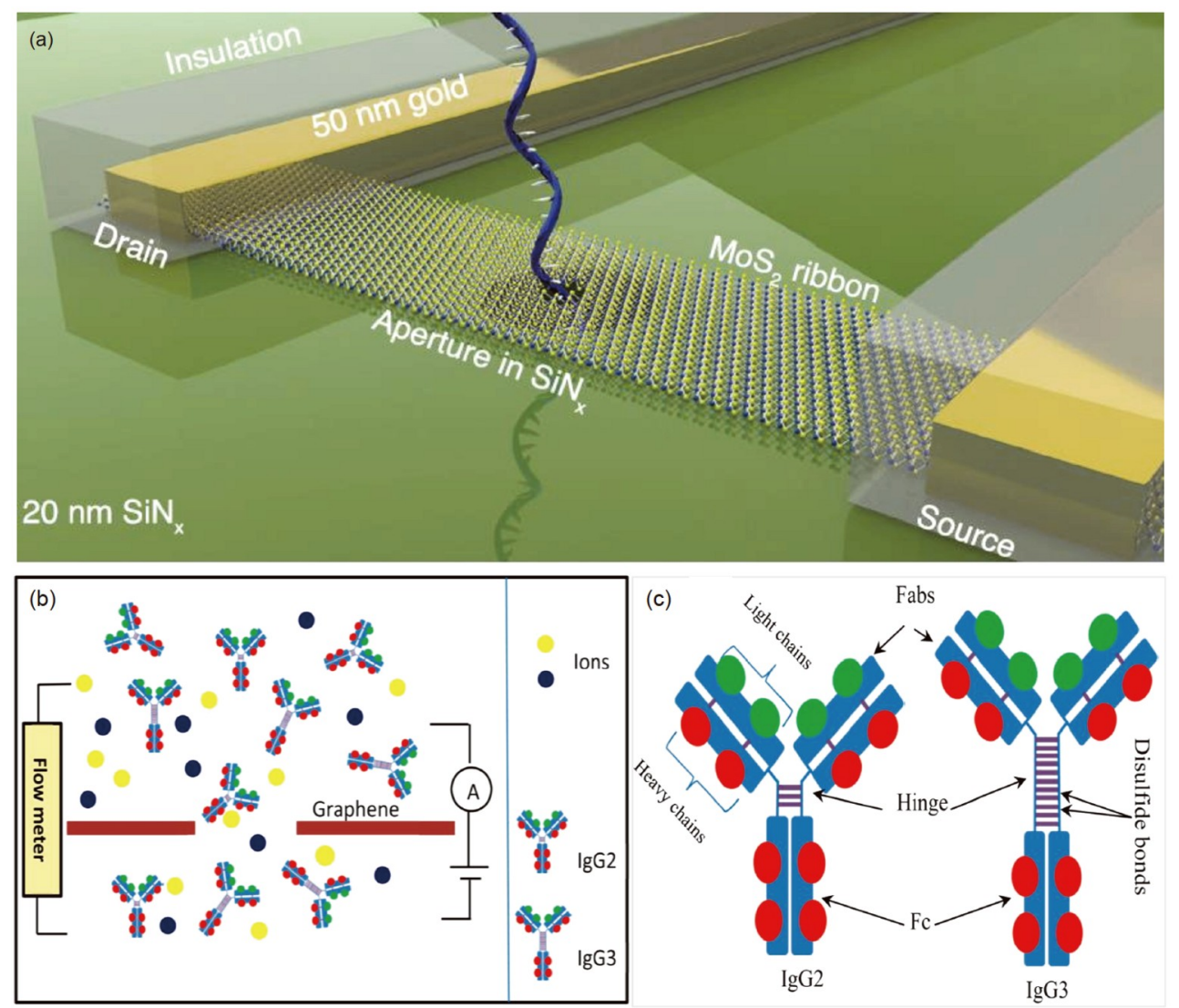

Figure 7 2D material-based nanopore detection of virus. (a) Schematic of a $\mathrm{MoS}_{2}$-based hybrid nanopore device for DNA detection by correlating the ionic current and the transverse current. Reproduced with permission from Ref. [138], copyright by American Chemical Society (2019). (b) Schematic of the detailed structure and working condition of the proposed nanopore graphene protein sensor. (c) Comparison of the structural differences in IgG2 and IgG3. The most obvious difference between IgG subclasses is the hinge region, which provides distinguishable signals in nanopore-based detection. Reproduced with permission from Ref. [147], copyright by American Chemical Society (2017) (color online).

current though the nanopore. It is noted that the nanopore on graphene can be elaborately tailored for various antibodies to get different current intensities (Figure 7b). The developed nanopore biosensor is capable of distinguishing subclasses of IgG antibodies with minor variation in atomic structures. The difference between various IgG subclasses is mostly in the hinge regions with variable number of amino acids and disulfide bonds in cysteine residues. Such difference results in the detectable signals in nanopore-based detection (Figure $7 \mathrm{c})$. This method employed versatile approaches to sensitively distinguish different IgG (IgG2 and IgG3) and even provide high-resolution spatial detection for IgG.

Additionally, photoelectrochemical (PEC) biosensing is a specific electrochemical analytical technique which is based on electrochemical analysis associated with photoexcitation processes. It requires the development of highly photoactive semiconductor materials for efficient electron-hole separation and enhanced photocurrent intensity to achieve high sensitivity. $2 \mathrm{D}$ materials, such as $\mathrm{g}-\mathrm{C}_{3} \mathrm{~N}_{4}$, have been incorporated into highly sensitive PEC biosensors for virus detection [148,149]. For instance, Qi et al. [148] reported a $2 \mathrm{D}$ extending $\mathrm{g}-\mathrm{C}_{3} \mathrm{~N}_{4}$ (g-CNS3) with excellent visible-light absorption and outstanding PEC performance as the photoactive layer in a PEC immunosensors for the detection of subgroup J avian leukosis virus. The developed PEC biosensor is capable of detecting target virus with a linear range of 102.14-103.35 $\mathrm{TCID}_{50} \mathrm{~mL}^{-1}$ and a LOD of 102.08 $\mathrm{TCID}_{50} \mathrm{~mL}^{-1}\left(\mathrm{TCID}_{50}: 50 \%\right.$ tissue culture infective dose). Another example was reported by Li et al. [149] in which a PEC biosensor based on the heterojunction of two 2D materials, $\mathrm{g}-\mathrm{C}_{3} \mathrm{~N}_{4}$ and $\mathrm{MoS}_{2}$. The heterojunction was further modified with CdSe QDs of high quantum efficiency for the co-sensitization effect. The PEC biosensor demonstrated high accuracy and responded linearly to the target DNA from $1.0 \mathrm{pM}$ to $2.0 \mu \mathrm{M}$ with a LOD as low as $0.32 \mathrm{pM}$. Another label-free $\mathrm{PEC}$ immunosensor was developed by $\mathrm{Wu}$ et al. [51] based on a photoactive matrix hybridizing $\mathrm{g}-\mathrm{C}_{3} \mathrm{~N}_{4}$ nanosheets and $\mathrm{Zn}_{0.1} \mathrm{Cd}_{0.9} \mathrm{~S}$ nanocrystals. This PEC immunosensor is capable of detecting CEA with a linear range of 0.005 to $20 \mathrm{ng} \mathrm{mL}^{-1}$ and a LOD of $1.4 \mathrm{pg} \mathrm{mL}^{-1}$ under optimized condition. The high sensitivity, specificity, accuracy, and reproducibility of PEC virus detection are considered to have promising potentials in viral analysis and clinical diagnosis. 


\section{Conclusions and prospect}

Timely and accurate virus detection plays a critical role in acquiring longer therapeutic time window and preventing the large-scale spread of highly transmissible and pathogenic viruses such as SAR-COV-2. 2D materials have shown great promise in the development of next-generation virus detection technologies. The extraordinary electronic and electrochemical properties, and the excellent flexibility of $2 \mathrm{D}$ materials make them promising in the FET and electrochemical virus detection. In addition, 2D materials also possess distinctive optical properties, such as efficient fluorescence quenching and surface Raman enhancement, enabling the design of novel optical virus detection including fluorescence, SERS, SPR, PEC and colorimetric biosensors. Besides, the unique 2D morphology of 2D materials is particularly advantageous for the burgeoning nanopore-based sequencing and sensing. Furthermore, 2D material-based virus detection shows great promise in clinical diagnosis and/or point-of-care devices with accurate and real-time readout. Despite the well-documented successes, there are still challenges in this increasingly important field. (1) Like many nanomaterials, the biotoxicity of 2D materials is still under investigation. In addition, the impurities, functionalization and exotic morphologies of $2 \mathrm{D}$ materials may also contribute to the toxicity of 2D materials [43]. Therefore, the biocompatibility and biotoxicity of 2D materials and their derivatives should be further explored. (2) Even though the preparation methods and functionalization approaches of $2 \mathrm{D}$ materials have been well developed, the properties of the asprepared materials are highly dependent on the preparation conditions. Therefore, more studies on large-scale preparation of 2D materials with reliable and stable properties are required for repeatable and reliable operation in virus detection. (3) The mechanism of interaction between biomolecules and 2D materials, including $\pi-\pi$ stacking, hydrogen bonding, electrostatic force, and van der Waals force [67], are not fully understood. Further efforts are expected to clarify fundamentals of the complex interaction between biomolecules and 2D materials to optimize the detection performance and reliability. (4) The emerging phase engineering of nanomaterials (PEN) is a versatile strategy that produces unconventional-phase $2 \mathrm{D}$ materials with unique properties and enhanced performance in various applications [150]. PEN can significantly modulate the electronic structures and interfacial properties of 2D materials which may benefit future virus detection technologies. (5) The further advancement of the field calls for more studies in practical clinical applications. Current studies are mainly focused on simulated physiological environments rather than actual clinical samples. The effects of many nonspecific interactions occurring in real samples are hardly taken into consideration, which could be one of the primary concerns regarding selectivity, sensitivity and more importantly, reliability of 2D material-based virus detection.

Acknowledgements H. Zhang thanks the support from ITC via the Hong Kong Branch of National Precious Metals Material Engineering Research Center (NPMM), the Research Grants Council of Hong Kong (AoE/P-701/ 20), the Start-Up Grant (9380100), the grants from the City University of Hong Kong (9610478, 9680314, 7020013, 1886921), and the Science Technology and Innovation Committee of Shenzhen Municipality (JCYJ20200109143412311, SGDX2020110309300301, "Preparation of single atoms on transition metal chalcogenides for electrolytic hydrogen evolution", CityU). Q. He acknowledges the funding support from the StartUp Grant $(7200656,9610482)$ and Grant from the City University of Hong Kong (7020013).

Conflict of interest The authors declare no conflict of interest.

1 Peiris JSM, Guan Y, Yuen KY. Nat Med, 2004, 10: S88-S97

2 Holmes EC, Dudas G, Rambaut A, Andersen KG. Nature, 2016, 538 : 193-200

3 Hutchinson EC. Trends Microbiol, 2018, 26: 809-810

4 Musso D, Gubler DJ. Clin Microbiol Rev, 2016, 29: 487-524

5 Pedersen SF, Ho YC. J Clin Invest, 2020, 130: 2202-2205

6 Guliy OI, Zaitsev BD, Borodina IA. Biosensors for Virus Detection. Macro, Micro, and Nano-Biosensors. Cham: Springer, 2021. 95-116

7 Ji T, Liu Z, Wang GQ, Guo X, Akbar Khan S, Lai C, Chen H, Huang S, Xia S, Chen B, Jia H, Chen Y, Zhou Q. Biosens Bioelectron, 2020, 166: 112455

8 Novoselov KS, Geim AK, Morozov SV, Jiang D, Zhang Y, Dubonos SV, Grigorieva IV, Firsov AA. Science, 2004, 306: 666-669

9 Chang C, Chen W, Chen Y, Chen Y, Chen Y, Ding F, Fan C, Jin Fan H, Fan Z, Gong C, Gong Y, He Q, Hong X, Hu S, Hu W, Huang W, Huang Y, Ji W, Li D, Li LJ, Li Q, Lin L, Ling C, Liu M, Liu N, Liu Z, Ping Loh K, Ma J, Miao F, Peng H, Shao M, Song L, Su S, Sun S, Tan C, Tang Z, Wang D, Wang H, Wang J, Wang X, Wang X, T. S. Wee A, Wei Z, Wu Y, Wu ZS, Xiong J, Xiong Q, Xu W, Yin P, Zeng H, Zeng Z, Zhai T, Zhang H, Zhang H, Zhang Q, Zhang T, Zhang X, Zhao LD, Zhao M, Zhao W, Zhao Y, Zhou KG, Zhou X, Zhou Y, Zhu H, Zhang H, Liu Z. Acta Physico Chim Sin, 2021, 0: 2108017-0

10 Wu Z, Qi J, Wang W, Zeng Z, He Q. J Mater Chem A, 2021, 9: 18793-18817

11 Chaturvedi A, Chen B, Zhang K, He Q, Nam G, You L, Lai Z, Tan C, Tran TH, Liu G, Zhou J, Liu Z, Wang J, Teo EHT, Zhang H. SmartMat, 2020, 1: e1011

12 Ménard-Moyon C, Bianco A, Kalantar-Zadeh K. ACS Sens, 2020, 5: 3739-3769

13 Morens DM, Folkers GK, Fauci AS. Nature, 2004, 430: 242-249

14 Stephenson JR, Alan W. Diagnostic Virology Protocols. Totowa: Humana Press, 2011

15 Kudesia G, Wreghitt T. Clinical and Diagnostic Virology. Cambridge: Cambridge University Press, 2009

16 Cugola FR, Fernandes IR, Russo FB, Freitas BC, Dias JLM, Guimarães KP, Benazzato $\mathrm{C}$, Almeida N, Pignatari GC, Romero $\mathrm{S}$, Polonio CM, Cunha I, Freitas CL, Brandão WN, Rossato C, Andrade DG, Faria DP, Garcez AT, Buchpigel CA, Braconi CT, Mendes E, Sall AA, Zanotto PMA, Peron JPS, Muotri AR, Beltrão-Braga PCB. Nature, 2016, 534: 267-271

17 Goldsmith CS, Miller SE. Clin Microbiol Rev, 2009, 22: 552-563

18 Badyda AJ, Dabrowiecki P, Lubinski W, Czechowski PO, Majewski G, Chcialowski A, Kraszewski A. Adv Exp Med Biol, 2013, 788: 229-235

19 Zamora JLR, Aguilar HC. Methods, 2018, 134-135: 87-97

20 Stern D, Pauly D, Zydek M, Miller L, Piesker J, Laue M, Lisdat F, Dorner MB, Dorner BG, Nitsche A. PLoS ONE, 2016, 11: e0150110 
21 Lee KH, Zeng H. Anal Chem, 2017, 89: 12743-12748

22 Freeman B, Lester S, Mills L, Rasheed MAU, Moye S, Abiona O, Hutchinson GB, Morales-Betoulle M, Krapinunaya I, Gibbons A, Chiang C-F, Cannon D, Klena J, Johnson JA, Owen SM, Graham BS, Corbett KS, Thornburg NJ. BioRxiv, 2020

23 Zhou Y, Wu Y, Ding L, Huang X, Xiong Y. TrAC Trends Anal Chem, 2021, 145: 116452

24 Storch GA. Clin Infect Dis, 2000, 31: 739-751

25 Zhu H, Fohlerová Z, Pekárek J, Basova E, Neužil P. Biosens Bioelectron, 2020, 153: 112041

26 Shin JH. Nucleic acid extraction techniques. In: Tang YW, Stratton C, Eds. Advanced Techniques in Diagnostic Microbiology. Boston: Springer, 2013. 209-225

27 Read SJ, Burnett D, Fink CG. J Clin Pathol, 2000, 53: 502-506

28 Santiago GA, Vázquez J, Courtney S, Matías KY, Andersen LE, Colón C, Butler AE, Roulo R, Bowzard J, Villanueva JM, MuñozJordan JL. Nat Commun, 2018, 9: 1391

29 Kashir J, Yaqinuddin A. Med Hypotheses, 2020, 141: 109786

30 Kunze A, Dilcher M, Abd El Wahed A, Hufert F, Niessner R, Seidel M. Anal Chem, 2016, 88: 898-905

31 Ramalingam N, San TC, Kai TJ, Mak MYM, Gong HQ. Microfluid Nanofluid, 2009, 7: 325

32 Shendure J, Balasubramanian S, Church GM, Gilbert W, Rogers J, Schloss JA, Waterston RH. Nature, 2017, 550: 345-353

33 Houldcroft CJ, Beale MA, Breuer J. Nat Rev Microbiol, 2017, 15: 183-192

34 Briese T, Kapoor A, Mishra N, Jain K, Kumar A, Jabado OJ, Lipkin WI. mBio, 2015, 6: e01491

35 Ding X, Yin K, Li Z, Lalla RV, Ballesteros E, Sfeir MM, Liu C. Nat Commun, 2020, 11: 4711

36 Ai JW, Zhang Y, Zhang HC, Xu T, Zhang WH. Emerging Microbes Infects, 2020, 9: 597-600

37 Shen Z, Xiao Y, Kang L, Ma W, Shi L, Zhang L, Zhou Z, Yang J, Zhong J, Yang D, Guo L, Zhang G, Li H, Xu Y, Chen M, Gao Z, Wang J, Ren L, Li M. Clin Infect Dis, 2020, 71: 713-720

38 Yan C, Cui J, Huang L, Du B, Chen L, Xue G, Li S, Zhang W, Zhao L, Sun Y, Yao H, Li N, Zhao H, Feng Y, Liu S, Zhang Q, Liu D, Yuan J. Clin Microbiol Infect, 2020, 26: 773-779

39 Rauch JN, Valois E, Solley SC, Braig F, Lach RS, Audouard M, Ponce-Rojas JC, Costello MS, Baxter NJ, Kosik KS, Arias C, Acosta-Alvear D, Wilson MZ. J Clin Microbiol, 2021, 59: e2402-20

40 Lucia C, Federico P-B, Alejandra GC. BioRxiv, 2020, doi: 10.1101/ 2020.02.29.971127

41 Seo G, Lee G, Kim MJ, Baek SH, Choi M, Ku KB, Lee CS, Jun S, Park D, Kim HG, Kim SJ, Lee JO, Kim BT, Park EC, Kim SI. ACS Nano, 2020, 14: 5135-5142

42 Li R, Pei S, Chen B, Song Y, Zhang T, Yang W, Shaman J. Science, 2020, 368: 489-493

43 Diao B, Wen K, Chen J, Liu Y, Yuan Z, Han C, Chen J, Pan Y, Chen L, Dan Y, Wang J, Chen Y, Deng G, Zhou H, Wu Y. MedRxiv, 2020

44 Ihling C, Tänzler D, Hagemann S, Kehlen A, Hüttelmaier S, Arlt C, Sinz A. J Proteome Res, 2020, 19: 4389-4392

45 Li Z, Yi Y, Luo X, Xiong N, Liu Y, Li S, Sun R, Wang Y, Hu B, Chen W, Zhang Y, Wang J, Huang B, Lin Y, Yang J, Cai W, Wang X, Cheng J, Chen Z, Sun K, Pan W, Zhan Z, Chen L, Ye F. J Med Virol, 2020, 92: 1518-1524

46 Chan JFW, Kok KH, Zhu Z, Chu H, To KKW, Yuan S, Yuen KY. Emerging Microbes Infects, 2020, 9: 221-236

47 Zhang H. ACS Nano, 2015, 9: 9451-9469

48 Chen W, Yan L, Bangal PR. Curr Alzheimer Resbon, 2010, 48: 1146-1152

49 Lawal AT. Biosens Bioelectron, 2018, 106: 149-178

50 Perumal Veeramalai C, Li F, Xu H, Kim TW, Guo T. RSC Adv, 2015, 5: $57666-57670$

51 Wu T, Zhang Y, Wei D, Wang X, Yan T, Du B, Wei Q. Sens Actuat B-Chem, 2018, 256: 812-819

52 Sun B, Dong J, Cui L, Feng T, Zhu J, Liu X, Ai S. Biosens Bioe- lectron, 2019, 124-125: 1-7

53 Wang Y, Hu Y, He Q, Yan J, Xiong H, Wen N, Cai S, Peng D, Liu Y, Liu Z. Biosens Bioelectron, 2020, 169: 112604

54 Zhu X, Zhang Y, Liu M, Liu Y. Biosens Bioelectron, 2021, 171: 112730

55 Wu S, He Q, Tan C, Wang Y, Zhang H. Small, 2013, 9: 1160-1172

56 Zhang S, Zhang D, Zhang X, Shang D, Xue Z, Shan D, Lu X. Anal Chem, 2017, 89: 3538-3544

57 Rohaizad N, Mayorga-Martinez CC, Fojtů M, Latiff NM, Pumera M. Chem Soc Rev, 2021, 50: 619-657

58 Ge Y, Shi Z, Tan C, Chen Y, Cheng H, He Q, Zhang H. Chem, 2020, 6: $1237-1253$

59 Tan C, Cao X, Wu XJ, He Q, Yang J, Zhang X, Chen J, Zhao W, Han S, Nam GH, Sindoro M, Zhang H. Chem Rev, 2017, 117: 6225-6331

60 Lai Z, He Q, Tran TH, Repaka DVM, Zhou DD, Sun Y, Xi S, Li Y, Chaturvedi A, Tan C, Chen B, Nam GH, Li B, Ling C, Zhai W, Shi Z, Hu D, Sharma V, Hu Z, Chen Y, Zhang Z, Yu Y, Renshaw Wang X, Ramanujan RV, Ma Y, Hippalgaonkar K, Zhang H. Nat Mater, 2021, 20: 1113-1120

61 Yu Y, Nam GH, He Q, Wu XJ, Zhang K, Yang Z, Chen J, Ma Q, Zhao M, Liu Z, Ran FR, Wang X, Li H, Huang X, Li B, Xiong Q, Zhang Q, Liu Z, Gu L, Du Y, Huang W, Zhang H. Nat Chem, 2018, 10: $638-643$

62 Wu S, Zeng Z, He Q, Wang Z, Wang SJ, Du Y, Yin Z, Sun X, Chen W, Zhang H. Small, 2012, 8: 2264-2270

63 Nasir MZM, Mayorga-Martinez CC, Sofer Z, Pumera M. ACS Nano, 2017, 11: 5774-5784

64 Wen W, Song Y, Yan X, Zhu C, Du D, Wang S, Asiri AM, Lin Y. Mater Today, 2018, 21: 164-177

65 He Q, Wu S, Yin Z, Zhang H. Chem Sci, 2012, 3: 1764-1772

66 Mao S, Chang J, Pu H, Lu G, He Q, Zhang H, Chen J. Chem Soc Rev, 2017, 46: 6872-6904

67 Park H, Han G, Lee SW, Lee H, Jeong SH, Naqi M, AlMutairi AA, Kim YJ, Lee J, Kim WJ, Kim S, Yoon Y, Yoo G. ACS Appl Mater Interfaces, 2017, 9: 43490-43497

68 Huang YC, Liu Y, Ma C, Cheng HC, He Q, Wu H, Wang C, Lin CY, Huang Y, Duan X. Nat Electron, 2020, 3: 59-69

$69 \mathrm{He} \mathrm{Q}, \mathrm{Wu} \mathrm{S}$, Gao S, Cao X, Yin Z, Li H, Chen P, Zhang H. ACS Nano, 2011, 5: 5038-5044

70 Mohanty N, Berry V. Nano Lett, 2008, 8: 4469-4476

71 Liu F, Kim YH, Cheon DS, Seo TS. Sens Actuat B-Chem, 2013, 186: 252-257

72 Chen Y, Ren R, Pu H, Guo X, Chang J, Zhou G, Mao S, Kron M, Chen J. Sci Rep, 2017, 7: 10974

73 Maity A, Sui X, Jin B, Pu H, Bottum KJ, Huang X, Chang J, Zhou G, Lu G, Chen J. Anal Chem, 2018, 90: 14230-14238

74 Jin X, Zhang H, Li YT, Xiao MM, Zhang ZL, Pang DW, Wong G, Zhang ZY, Zhang GJ. Microchim Acta, 2019, 186: 223

75 Zhang X, Qi Q, Jing Q, Ao S, Zhang Z, Ding M, Wu M, Liu K, Wang W, Ling Y. arXiv preprint, arxiv: 2003.12529, 2020

76 Hideshima S, Hayashi H, Hinou H, Nambuya S, Kuroiwa S, Nakanishi T, Momma T, Nishimura SI, Sakoda Y, Osaka T. Sci Rep, 2019, 9: 11616

77 Kwon J, Lee Y, Lee T, Ahn JH. Anal Chem, 2020, 92: 5524-5531

78 Roberts A, Chauhan N, Islam S, Mahari S, Ghawri B, Gandham RK, Majumdar SS, Ghosh A, Gandhi S. Sci Rep, 2020, 10: 14546

79 Aspermair P, Mishyn V, Bintinger J, Happy H, Bagga K, Subramanian P, Knoll W, Boukherroub R, Szunerits S. Anal Bioanal Chem, 2021, 413: 779-787

80 Islam S, Shukla S, Bajpai VK, Han YK, Huh YS, Kumar A, Ghosh A, Gandhi S. Biosens Bioelectron, 2019, 126: 792-799

81 Chan C, Shi J, Fan Y, Yang M. Sens Actuat B-Chem, 2017, 251: $927-$ 933

82 Sarkar D, Liu W, Xie X, Anselmo AC, Mitragotri S, Banerjee K. ACS Nano, 2014, 8: 3992-4003

83 Liu J, Chen X, Wang Q, Xiao M, Zhong D, Sun W, Zhang G, Zhang Z. Nano Lett, 2019, 19: 1437-1444 
84 Fathi-Hafshejani P, Azam N, Wang L, Kuroda MA, Hamilton MC, Hasim S, Mahjouri-Samani M. ACS Nano, 2021, 15: 11461-11469

85 Lu C, Liu Y, Ying Y, Liu J. Langmuir, 2017, 33: 630-637

86 Nagar B, Balsells M, de la Escosura-Muñiz A, Gomez-Romero P, Merkoçi A. Biosens Bioelectron, 2019, 129: 238-244

87 Li J, Li Y, Zhai X, Cao Y, Zhao J, Tang Y, Han K. Electrochem Commun, 2020, 110: 106601

88 Gong Q, Han H, Yang H, Zhang M, Sun X, Liang Y, Liu Z, Zhang W, Qiao J. J Materiomics, 2019, 5: 313-319

89 Xiang Q, Huang J, Huang H, Mao W, Ye Z. RSC Adv, 2018, 8: 1820 1825

90 Wang T, Zhu R, Zhuo J, Zhu Z, Shao Y, Li M. Anal Chem, 2014, 86: 12064-12069

91 Wang X, Nan F, Zhao J, Yang T, Ge T, Jiao K. Biosens Bioelectron, 2015, 64: 386-391

92 Liu X, Shuai HL, Liu YJ, Huang KJ. Sens Actuat B-Chem, 2016, 235: 603-613

93 Singhal C, Khanuja M, Chaudhary N, Pundir CS, Narang J. Sci Rep, 2018, 8: 7734

94 Li F, Li Y, Feng J, Gao Z, Lv H, Ren X, Wei Q. Biosens Bioelectron, 2018, 100: 512-518

95 Giang H, Pali M, Fan L, Suni II. Electroanalysis, 2019, 31: 957-965

96 Tian J. Int J Electrochem Sci, 2017, 12: 2658-2668

97 Anik Ü, Tepeli Y, Sayhi M, Nsiri J, Diouani MF. Analyst, 2018, 143: $150-156$

98 Gao Z, Li Y, Zhang X, Feng J, Kong L, Wang P, Chen Z, Dong Y, Wei Q. Biosens Bioelectron, 2018, 102: 189-195

99 Singh R, Hong S, Jang J. Sci Rep, 2017, 7: 42771

100 Huang J, Xie Z, Huang Y, Xie L, Luo S, Fan Q, Zeng T, Zhang Y, Wang S, Zhang M, Xie Z, Deng X. Sci Rep, 2020, 10: 13869

101 Su S, Han X, Lu Z, Liu W, Zhu D, Chao J, Fan C, Wang L, Song S, Weng L, Wang L. ACS Appl Mater Interfaces, 2017, 9: 12773-12781

102 Li X, Wang Y, Zhang X, Gao Y, Sun C, Ding Y, Feng F, Jin W, Yang G. Microchim Acta, 2020, 187: 217

103 Zhou D, Wang M, Dong J, Ai S. Electrochim Acta, 2016, 205: 95101

104 Liu C, Dong J, Ning S, Hou J, Waterhouse GIN, Cheng Z, Ai S. Microchim Acta, 2018, 185: 423

105 Zhang H, Zhang H, Aldalbahi A, Zuo X, Fan C, Mi X. Biosens Bioelectron, 2017, 89: 96-106

106 Wen J, Li W, Li J, Tao B, Xu Y, Li H, Lu A, Sun S. Sens Actuat BChem, 2016, 227: 655-659

107 Waiwijit U, Phokaratkul D, Kampeera J, Lomas T, Wisitsoraat A, Kiatpathomchai W, Tuantranont A. J Biotechnol, 2015, 212: 44-49

108 Kong RM, Ding L, Wang Z, You J, Qu F. Anal Bioanal Chem, 2015, 407: $369-377$

109 Singh P, Gupta R, Sinha M, Kumar R, Bhalla V. Microchim Acta, 2016, 183: 1501-1506

110 Kenry, Geldert A, Zhang X, Zhang H, Lim CT. ACS Sens, 2016, 1: 1315-1321

111 Oudeng G, Au M, Shi J, Wen C, Yang M. ACS Appl Mater Interfaces, 2018, 10: 350-360

112 Achadu OJ, Takemura K, Khoris IM, Park EY. Sens Actuat B-Chem, 2020, 321: 128494

113 Peng X, Zhang Y, Lu D, Guo Y, Guo S. Sens Actuat B-Chem, 2019, 286: 222-229

114 Ling X, Xie L, Fang Y, Xu H, Zhang H, Kong J, Dresselhaus MS, Zhang J, Liu Z. Nano Lett, 2010, 10: 553-561

$115 \mathrm{Xu}$ W, Ling X, Xiao J, Dresselhaus MS, Kong J, Xu H, Liu Z, Zhang J. Proc Natl Acad Sci USA, 2012, 109: 9281-9286

116 Ling X, Fang W, Lee YH, Araujo PT, Zhang X, Rodriguez-Nieva JF, Lin Y, Zhang J, Kong J, Dresselhaus MS. Nano Lett, 2014, 14: 30333040

117 Jiang J, Zou J, Wee ATS, Zhang W. Sci Rep, 2016, 6: 34599

118 Li Z, Jiang S, Xu S, Zhang C, Qiu H, Chen P, Gao S, Man B, Yang C, Liu M. J Alloys Compd, 2016, 666: 412-418

119 Sarycheva A, Makaryan T, Maleski K, Satheeshkumar E, Melikyan
A, Minassian H, Yoshimura M, Gogotsi Y. J Phys Chem C, 2017, 121: $19983-19988$

120 He S, Liu KK, Su S, Yan J, Mao X, Wang D, He Y, Li LJ, Song S, Fan C. Anal Chem, 2012, 84: 4622-4627

121 Yang L, Zhen SJ, Li YF, Huang CZ. Nanoscale, 2018, 10: 11942 11947

122 Achadu OJ, Abe F, Suzuki T, Park EY. ACS Appl Mater Interfaces, 2020, 12: 43522-43534

123 Wong WR, Sekaran SD, Mahamd Adikan FR, Berini P. Biosens Bioelectron, 2016, 78: 132-139

124 Omar NAS, Fen YW, Abdullah J, Sadrolhosseini AR, Mustapha Kamil Y, Fauzi NIM, Hashim HS, Mahdi MA. Nanomaterials, 2020, 10: 569

125 Omar NAS, Fen YW, Abdullah J, Kamil YM, Daniyal WMEMM, Sadrolhosseini AR, Mahdi MA. Sci Rep-Uk, 2020, 10: 1-15

126 Omar NAS, Fen YW, Abdullah J, Zaid MHM, Daniyal WMEMM, Mahdi MA. Optics Laser Tech, 2019, 114: 204-208

127 Chiu NF, Fan SY, Yang CD, Huang TY. Biosens Bioelectron, 2017, 89: $370-376$

128 Chiu NF, Lin TL. Talanta, 2018, 185: 174-181

129 Nie W, Wang Q, Yang X, Zhang H, Li Z, Gao L, Zheng Y, Liu X, Wang K. Anal Chim Acta, 2017, 993: 55-62

130 Zhan L, Li CM, Wu WB, Huang CZ. Chem Commun, 2014, 50: $11526-11528$

131 Zhang YW, Liu WS, Chen JS, Niu HL, Mao CJ, Jin BK. Sens Actuat B-Chem, 2020, 321: 128456

132 Liu Y, Nie Y, Wang M, Zhang Q, Ma Q. Biosens Bioelectron, 2020, 148: 111823

133 Wells DB, Belkin M, Comer J, Aksimentiev A. Nano Lett, 2012, 12: 4117-4123

134 Lee K, Park KB, Kim HJ, Yu JS, Chae H, Kim HM, Kim KB. $A d v$ Mater, 2018, 30: 1704680

135 Chen W, Liu GC, Ouyang J, Gao MJ, Liu B, Zhao YD. Sci China Chem, 2017, 60: 721-729

136 Crick CR, Sze JYY, Rosillo-Lopez M, Salzmann CG, Edel JB. ACS Appl Mater Interfaces, 2015, 7: 18188-18194

137 Shankla M, Aksimentiev A. ACS Appl Mater Interfaces, 2020, 12: 26624-26634

138 Graf M, Lihter M, Altus D, Marion S, Radenovic A. Nano Lett, 2019, 19: 9075-9083

139 Danda G, Masih Das P, Chou YC, Mlack JT, Parkin WM, Naylor CH, Fujisawa K, Zhang T, Fulton LB, Terrones M, Johnson ATC, Drndić M. ACS Nano, 2017, 11: 1937-1945

140 Garaj S, Hubbard W, Reina A, Kong J, Branton D, Golovchenko JA. Nature, 2010, 467: 190-193

141 Garaj S, Liu S, Golovchenko JA, Branton D. Proc Natl Acad Sci USA, 2013, 110: 12192-12196

142 Arima A, Harlisa IH, Yoshida T, Tsutsui M, Tanaka M, Yokota K, Tonomura W, Yasuda J, Taniguchi M, Washio T, Okochi M, Kawai T. J Am Chem Soc, 2018, 140: 16834-16841

143 Arima A, Tsutsui M, Harlisa IH, Yoshida T, Tanaka M, Yokota K, Tonomura W, Taniguchi M, Okochi M, Washio T, Kawai T. Sci Rep, 2018, 8: 16305

144 Arima A, Tsutsui M, Washio T, Baba Y, Kawai T. Anal Chem, 2021, 93: $215-227$

145 Darvish A, Lee JS, Peng B, Saharia J, VenkatKalyana Sundaram R, Goyal G, Bandara N, Ahn CW, Kim J, Dutta P, Chaiken I, Kim MJ. Electrophoresis, 2019, 40: 776-783

146 Oh S, Lee MK, Chi SW. ACS Sens, 2019, 4: 2849-2853

147 Barati Farimani A, Heiranian M, Min K, Aluru NR. J Phys Chem Lett, 2017, 8: 1670-1676

148 Qi H, Sun B, Dong J, Cui L, Feng T, Ai S. Sens Actuat B-Chem, 2019, 285: 42-48

149 Li PP, Liu XP, Mao CJ, Jin BK, Zhu JJ. Anal Chim Acta, 2019, 1048: $42-49$

150 Chen Y, Lai Z, Zhang X, Fan Z, He Q, Tan C, Zhang H. Nat Rev Chem, 2020, 4: 243-256 